\title{
Relación entre el Estado descentralizado y la sociedad civil territorial: contexto, bondades y limitaciones en América Latina
}

\section{The relationship between the descentralised State and the territorial civil society: context, benefits and limitations in Latin America}

\author{
Carlos Mascareño Quintana*
}

\begin{abstract}
Even though in Latin America it is possible to observe processes of descentralisation emerging from the articulation of State and society, it is necessary to recognise that there are still a number of practices and cultures that can be described as populist, patrimonialist and clientelist, which hinder the efforts of the citizen participation. This paper analyses the origin and development of the relationship between State and civil society, emphasising the territorial dimension associated to the democratisation and consolidation of social movements in Latin America. We also explore the performance of the descentralisation processes and some of their characteristics in relationship to the political discourses from which they emerged. Finally, we evaluate the benefits of this relationship and most importantly the limitations regarding its contribution to the democratic process in the region.
\end{abstract}

Keywords: descentralisation, State, civil society, Latin America.

\section{Resumen}

Si bien es cierto que en América Latina se advierten procesos de descentralización surgidos de la articulación Estado-sociedad, es preciso reconocer que aún prevalecen prácticas y culturas políticas populistas, patrimonialistas y clientelares que disminuyen (e incluso invalidan) el efecto de los esfuerzos de participación ciudadana. El presente trabajo analiza el origen y desarrollo de la relación Estado-sociedad civil, enfatizando la dimensión territorial asociada a la democratización y la consolidación de los movimientos sociales en América Latina. Posteriormente explora el desempeño de los procesos de descentralización y algunas de sus particularidades, en relación con el discurso político que los justificó. Por último, evalúa las bondades de dicha relación y, sobre todo, las limitaciones en cuanto a su contribución a los procesos democráticos de la región.

Palabras clave: descentralización, Estado, sociedad civil, Latinoamérica

*Universidad Central de Venezuela, Venezuela. Correo-e: mascaren@cantv.net 


\section{Introducción}

La necesidad de dirigir las repúblicas hacia un estadio de democracia política y social se constituyó en una de las principales inspiraciones de los procesos de descentralización en América Latina, tanto en el plano de la discusión de las ideas iniciada en los años setenta como en su posterior y progresiva implementación. Esta reforma se convirtió en una respuesta frontal a la amplia vigencia de regímenes autoritarios que se habían constituido en límite para avanzar hacia la implantación de un Estado que sea más sensible a la población.

En ese contexto, la descentralización del Estado se explicaba y se requería como reacción natural ante el largo predominio del Estado centralizado, modelo funcional del proceso de crecimiento hacia adentro en crisis que ya no satisfacía a la mayoría de los latinoamericanos. Así, la descentralización vino de la mano de la democratización, en tanto instrumento del cual se esperaba que facilitara la cercanía de los habitantes a las estructuras de gobierno y, con ello, a la toma de decisiones, con lo que se intentaría neutralizar la excesiva discrecionalidad de los funcionarios y se enfrentaría el autoritarismo asociado a la centralización del poder.

De manera concomitante, el declive del modelo centralizado de Estado y de economías sustitutivas de importaciones, así como el crecimiento y consolidación de las ciudades, determinó la aparición de nuevos actores sociales, diferentes a los que habían formado parte de los pactos corporativos -partidos, sindicatos y empresarios-, que reclamaban su inclusión en el debate de los grandes asuntos nacionales, cuestionando los consensos tripartitos que monopolizaban las decisiones públicas. En esa perspectiva, las esperanzas transformadoras que se colocaron sobre los hombros de los nuevos movimientos sociales eran el factor que alimentaba la reflexión en el inicio de la transición. Uno de los elementos que resaltaron en ésta fue la imperiosa necesidad de introducir cambios sustantivos que impidieran regresar a los férreos autoritarismos militares o permitieran avanzar hacia una mayor apertura democrática en aquellos países donde ya existían democracias representativas -Colombia, Costa Rica y Venezuela- o donde predominaba un autoritarismo de partido único, como en México. Por ello, revisar la relación entre el Estado autoritario y la sociedad civil latinoamericana se convertía en una tarea colectiva y de cumplimiento obligatorio. 
Democratización, creación y desarrollo de nuevas formas de organización social y descentralización del Estado constituyeron procesos que fueron parte de una misma dinámica de cambio y se imbricaron hasta construir un discurso alrededor de la participación ciudadana como medio redentor para superar las prácticas dominantes en la relación Estado autoritario-sociedad civil. En este contexto, las múltiples formas de organización ciudadana que surgieron en los territorios subnacionales -municipios o entidades intermedias (provincias, regiones, estados)- han transitado un largo camino de interacción con las estructuras del Estado descentralizado -sean alcaldías, gobernaciones o entes legislativos locales-, con la esperanza de que sus aportaciones puedan contribuir al mantenimiento y profundización de las democracias latinoamericanas.

Casi tres décadas han transcurrido desde el inicio de esta dinámica y, sin duda, América Latina muestra hoy un rostro más democrático y más descentralizado. Sin embargo, las preocupaciones acerca de las limitaciones que se observan en la relación Estado descentralizado-sociedad civil territorial, plagada de autoritarismos, patrimonialismo y resistencias a la transparencia y el control ciudadano, hacen dudar de la eficacia de la descentralización como mecanismo democratizador y propician interrogantes acerca de si este proceso posee la suficiente capacidad para propiciar una rearticulación entre el Estado y la sociedad, sobre todo a través de los mecanismos de participación local que han plagado la escena institucional latinoamericana.

El presente artículo intenta ofrecer una perspectiva de la dinámica latinoamericana respecto de la relación en cuestión. Para ello, en un primer apartado se desarrolla una breve discusión contextual acerca de las ideas iniciales sobre los movimientos sociales, las sociedades civiles y el inicio de las democracias. En la segunda parte se discuten de manera sintética los orígenes de la descentralización asociados a la democratización de América Latina. En la tercera sección se aborda el tema central de este trabajo: la relación entre el Estado descentralizado y la sociedad civil territorial, con énfasis en las realidades predominantes tanto desde la oferta de participación del Estado como desde la que plantea la sociedad civil, sus bondades y las limitaciones que se advierten. En el último punto se presentan comentarios de cierre sobre el tema de reflexión. 


\section{Transición democrática y movimientos sociales: la difícil rearticulación Estado-sociedad en América Latina}

Como dijo Alfred Stepan en los ochenta, "la sociedad civil se convirtió en la celebridad política de muchas y recientes transiciones latinoamericanas de mandatos autoritarios" (citado en Escobar et al., 2001: 39). En esa línea de pensamiento, se reconocía cómo las múltiples y variadas organizaciones sociales conformadas en los setenta, en medio de férreos regímenes autoritarios, se habían convertido en un nuevo sujeto de la política, por lo que se imponía la necesidad de aprovechar las posibilidades de la democracia liberal para construir una alternativa de cambio social (Pease García, 1983). La idea de transición aludía a la necesidad de superar las dictaduras latinoamericanas, sobre todo las de Brasil, el Cono Sur y Centroamérica. Lechner (1994) recordaría tiempo después cómo la conferencia de Clacso de 1978, en Costa Rica, había marcado un hito al plantear la democracia (y con ella la presencia de nuevas organizaciones sociales) como el eje del debate político intelectual de América Latina.

Al inicio de la transición, los nuevos movimientos sociales representaban una ascendente y decisiva fuerza social estructurada como frentes, organizaciones de base y comités de defensa que actuaban independientemente de los partidos y que se proponían una permanente lucha por la sobrevivencia y por la eliminación de las condiciones políticas y económicas que los enajenaban (Kärner, 1983). Ante esta perspectiva optimista, Gorlier (1992) advirtió acerca de la sobreexpectativa que se le daba a estos grupos, de los cuales se esperaba un comportamiento democratizador, de influencia política y que, en definitiva, se convirtiesen en actores centrales de una nueva megahistoria cuya acción estaba asociada a una diversidad de aspectos tales como asuntos de identidad, autonomía territorial, democracia de base, ciudadanía social, cotidianidad, entre otras áreas del acontecer colectivo. Por su parte, Mainwaring (en Gómez-Calcaño, 1992) introdujo ajustes en sus hipótesis optimistas sobre el potencial democratizador de los movimientos sociales, cuando observó -a partir de las realidades de Brasil y Argentina- cómo estos países, lejos de reagruparse luego de iniciada la transición y luchar por el mantenimiento de la democracia, actuaban de manera dispersa y competitiva por el acceso a los recursos del Estado. A pesar de esta perspectiva, se sostenía que no había que perder de vista las contribuciones de los movimientos sociales que surgieron en 
los ochenta, los cuales representaban canales para incorporar y ampliar los temas de la agenda política democrática. Por otro lado, si bien se reconocía el carácter democratizador de las organizaciones sociales en ascenso, se recomendaba colocar en el centro del debate la desconfianza por la implantación de una especie de ideología de la participación que provenía de los gobiernos, ahora democráticos y varios de ellos descentralizados, con lo cual se intentaba absorber el potencial de protesta de los movimientos sociales (Uribe, 1987)

¿Sería entonces posible, en esa tendencia a la debilidad de la sociedad civil representada en los movimientos sociales, superar el estadocentrismo asociado al autoritarismo latinoamericano y lograr una esfera pública autónoma? ¿Cómo transitar desde una sociedad con una conciencia colectiva fundada en el estadocentrismo y el autoritarismo como forma normal de vida hacia otra en la cual se recompusieran los mapas cognitivos, las viejas adhesiones ideológicas y las visiones acerca de lo que debería ser la comunidad de ciudadanos? Ese era, en consecuencia, el reto que atravesaban las democracias emergentes y su intento por rearticularse con las múltiples y crecientes organizaciones sociales.

La matriz estadocéntrica en América Latina, como lo argumenta Cavarozzi (1995), no tuvo flexibilidad. Fue frágil y rígida al mismo tiempo y, al debilitarse sus mitos fundacionales, los procedimientos para la toma de decisiones no contribuyeron a reforzar la legitimidad de los regímenes nacientes en los que se apoyaban los procesos de abajo hacia arriba. Alberto Olvera y Leonardo Avritzer (1992), al analizar la realidad mexicana, afirman que, precisamente, la secular fusión entre economía, sociedad y Estado hizo que el protagonismo de los cambios de la historia se le asignara al Estado y, por ello, fue convertido "en el portador del proyecto, alma de la revolución y punto de equilibrio de las anárquicas fuerzas sociales. La tradición estatólatra de la ciencia social mexicana en particular y latinoamericana en general, tiene que ver con el enorme peso del Estado en nuestras sociedades, con su carácter patrimonial y con el atraso relativo de la organización independiente de la sociedad" (Olvera y Avritzer, 1992: 227).

En cuanto a las transiciones políticas en México y Perú, Morgan Quero (2004) se pregunta hasta dónde la vigencia del modelo contractualista que deriva en relaciones clientelares dominantes, no resulta ser la mayor limitación para una sociedad civil vigorosa capaz de ser interlocutor del gobierno sin que necesa- 
riamente quiera ser gobierno. Efectivamente, las relaciones de las organizaciones sociales con las élites en las transiciones (México desde 1988 y Perú desde 1990), rememoran al contractualismo en el final del régimen colonial en el cual se pudieron establecer numerosos pactos políticos con los municipios para defender sus autonomías, redefiniéndose, de este modo, la ciudadanía liberal por parte de las culturas locales para enfrentar los dilemas de la futura gobernabilidad republicana, tal como lo sostiene Annino (citado por Quero, 2004: 8).

Esta debilidad en la relación de los movimientos sociales que alimentan la sociedad civil latinoamericana en las últimas décadas con el Estado democrático, tiene su origen, desde la perspectiva de Philip Oxhorn (2003), en las limitaciones de la esfera pública, lo que contribuye a una creciente distancia entre una élite política y la gente que supuestamente representa. En América Latina, insiste el autor, la falta de impacto de los movimientos sociales puede alimentar la frustración, a la vez que la heterogeneidad social limita la acción colectiva y termina reforzando las jerarquías sociales. De la misma forma, los actores locales, que representan la mayoría de las actividades organizativas de base identitaria, no logran trascender hacia la agenda pública nacional en una región en la cual "centenarias tendencias centralizadoras aún predominan, a pesar de los recientes esfuerzos para descentralizar al Estado en muchos países" (Oxhorn, 2003: 135).

¿Cómo se hace, entonces, para que la transición democrática sea posible en medio de una clara debilidad de la sociedad civil expresada en numerosos y crecientes grupos que actúan aisladamente? ¿Cómo hablar de consolidación democrática en un mar de desencuentros entre la sociedad política y la sociedad civil?

En los primeros tiempos de la redemocratización latinoamericana, la palabra emblemática fue transición y las nuevas formas de hacer y pensar la política se convirtieron en obsesión para el pensamiento ideológico en el subcontinente (Rabotnikof, 1992). ¿Podrían sobrevivir las frágiles y nacientes democracias latinoamericanas y extender los principios básicos de ciudadanía a las esferas económica y social o correrían el riesgo de su desconsolidación?, se preguntaba Terry Karl (1995). Las respuestas no podrían lograrse por la vía de los análisis convencionales que buscaban el cumplimiento de los requisitos de la democracia sino, en otra visión, habría que asumir el carácter contingente de los procesos en marcha, cuya posibilidad de éxito dependería de factores adoptados en las distintas realidades nacionales. Así, las 
perspectivas formuladas por Karl para Perú eran descorazonadoras y tuvo razón: Fujimori se convirtió en el nuevo autócrata y la relación democrática con la sociedad peruana de nuevo se hundió en las formas históricas dominantes.

Lo que entonces sucedió, de acuerdo con Alberto Olvera (2003), es que las múltiples y complejas relaciones entre la sociedad civil y los gobiernos, si bien pueden producir interesantes procesos de participación -sobre todo en los gobiernos locales-, terminan insertas en la reproducción de las formas de dominación tradicional de la sociedad civil por parte de la sociedad política. En esa dinámica destaca, sobre todo, la falta de ideas sobre lo que significa el ejercicio democrático del poder, por lo que los actores al final atraviesan un largo y conflictivo proceso de interacción que no necesariamente propicia aprendizaje.

Esa debilidad se sustenta en el hecho de que, en general, las formas de participación se institucionalizaban desde la perspectiva de la oferta oficial tanto en el ámbito de las políticas nacionales como de las regionales y locales. Si bien era deseable la oferta estatal de participación, "en la mayoría de los casos, es el Estado quien decide la legitimidad de los intereses de los grupos sociales y determina el acceso diferencial que cada uno tiene a sus centros de decisión" (Cunill, 1991: 187), por lo que los medios existentes de relación Estado-sociedad asomaban sus limitaciones para contribuir con la democratización de América Latina. En un trabajo posterior, la misma autora se plantearía, tratando de ir más allá de los enfoques autocentrados en la relación misma, la siguiente interrogante: “¿cómo el Estado puede desarrollar condiciones favorables para la acción privada, que preserven a la vez la autonomía social y el ejercicio de la responsabilidad pública?" (Cunill, 1995: 49).

La reflexión sobre la rearticulación del Estado y la sociedad, a propósito de los procesos de la democratización en marcha en Latinoamérica, entraron en el terreno de las dudas -cuando no de las frustraciones- desde el momento en que las ofertas de participación y presencia ciudadana en los asuntos públicos continuaban circunscritas al control del Estado y a la instrumentalización mediante la oferta de los programas de ajuste, sobre todo en el campo de la política social.

En medio de aquellas dificultades, los procesos de reforma del Estado latinoamericano continuaron impulsándose como medio para crear un ambiente institucional que facilitara mayor acceso de los ciudadanos a las decisiones públicas. A su vez, era 
innegable la irrupción de diversas organizaciones sociales, al calor de los procesos democráticos en casi todos los países de la región. En ambos casos, se iba tras la pista de una nueva articulación entre el Estado y la sociedad, camino en el cual habían surgido prescripciones y utopías que representaban la carta de navegación intelectual para intervernir y construir tal proceso de rearticulación. Sin embargo, a pesar de las argumentaciones anteriores, la esfera pública continuaba débil y, en consecuencia, las bases de la democracia.

Para amortiguar el férreo carácter estadocéntrico de nuestras repúblicas se utilizaron las reformas para descentralizar al Estado y, en su rol de acompañantes de las transiciones, tratar de introducir formas más democráticas en la relación de las organizaciones sociales, en particular las de carácter territorial, con las estructuras de gobierno que se han consolidado con el tiempo. Así, la descentralización es una pieza clave en las relaciones del Estado con la sociedad, por lo que es necesario discutir su origen y relación con las variables antes abordadas.

\section{La descentralización latinoamericana: una nueva manera de concebir la relación Estado-sociedad civil}

De manera notable y dominante, el discurso que justifica la descentralización del Estado latinoamericano en los ochenta se basó, entre otras perspectivas, en una visión política del asunto. ${ }^{1}$ Dentro de este pensamiento, la relación entre democracia y descentralización era el pilar fundamental del argumento. Así, se esperaba que la reforma en cuestión ampliara los horizontes democráticos al acercar a los ciudadanos a sus gobernantes, permitiéndoles un mayor acceso a las decisiones sobre los asuntos públicos y, con ello, lograr una mejor calidad democrática e impedir la regresión autoritaria. Esta expectativa incluía, a su vez, otra argumentación fundamental: si la descentralización es lo antes anunciado, los movimientos sociales -fraguados al calor de la prolongada crisis política de los sesenta y setenta- pasarán a ser actores clave en la rearticulación del Estado y la sociedad,

\footnotetext{
${ }^{1}$ Es innegable la presencia de una perspectiva económica en el discurso descentralizador latinoamericano, articulado sobre la base de una mayor eficiencia y eficacia en los servicios públicos centralizados. Sin embargo, el mismo terminó formando parte de la esfera de lo político, en tanto que esos objetivos, al pretender atacar la crisis del abultado e ineficiente Estado central, abonaron el camino para pactar una nueva distribución del poder en la mayoría de los países latinoamericanos.
} 
aprovechando un marco constitucional y jurídico descentralizado que confiere ventajas para la estrategia en cuestión.

Era tan contundente la visión sobre la relación entre democracia y descentralización que se argumentaba que, en mayor o menor medida, América Latina había tenido un nuevo punto de partida en su retorno a la democracia, lo cual suponía una revisión profunda del régimen territorial del Estado. Esa revisión, a su vez, se inscribió en un debate que en el ámbito mundial se venía suscitando sobre la revaloración de lo local en la búsqueda de nuevos paradigmas de desarrollo y de nuevos vínculos entre el Estado y la sociedad. Ello suponía, en consecuencia, el fortalecimiento de las identidades locales y la presencia de distintas formas de representación y gestión de intereses a partir de la presencia de las organizaciones de base territorial (Bervejillo, 1991).

Tan cierta y determinante era la idea sobre la relación en cuestión, que para el caso brasileño, país con una tradición federal republicana asfixiada bajo la impronta de los regímenes militares, se afirmaría lo siguiente:

En el Brasil contemporáneo [...] hay la concepción generalizada de que existe una relación directa entre descentralización y democratización. La historia de la lucha por la democracia en nuestro país en las tres últimas décadas, envolvió y se basó en gran proporción en la conquista de la autonomía municipal y la autonomía de los estados de la Federación [...] Una de las primeras conquistas en el reciente proceso de redemocratización en el Brasil fue la elección directa de los gobernadores de los estados de la Federación (1982), prohibida durante los gobiernos militares y, después, la elección directa de los alcaldes de las capitales estadales (1985). Estos alcaldes, como los gobernadores, eran escogidos personalmente por los generales-presidentes [...] esta ausencia de autonomía real caracterizaba la federación en el Brasil antes de la Constitución de 1988 (Maranhao, 1991: 284).

Tal era la simbiosis entre descentralización y democracia que en la Argentina de los ochenta se llegó a hablar de refederalización del sistema político, como una expresión que denotaba la pérdida del sentido federal que tuvo este país a lo largo de su historia republicana. En esa línea de pensamiento, afirma Martha Díaz de Landa (1991), la profundización centralista de la Argentina llevó a la desfederalización del sistema político y el estancamiento de zonas geográficas a favor de Buenos Aires. Al respecto, afirma la autora, la centralización más acabada se logró durante los gobiernos militares. Por ello, una de las tendencias naturales durante la actual apertura democrática, es la refe- 
deralización del sistema político y la democratización de la relación entre el Estado y la sociedad. Por ello, para que exista una asociación entre democratización y ampliación de los grados de participación política y social, necesariamente tiene que existir algún grado de descentralización para las decisiones y la instrumentación de las políticas públicas (Ibidem). El camino argentino no fue fácil. Si bien era posible constatar intentos, avances y retrocesos en el proceso de distribución de los recursos, atribuciones y poder, no fue sino hasta la Ley de Transferencias de Servicios de 1991 que pudiera hablarse con propiedad de un proceso de reforma de segunda generación, inicio que se reforzará por los pactos federales de 1991, 1993, 1999 y 2000 (Smulovitz y Clemente, 2004).

México, con su federalismo centralizado y de partido único, introdujo reformas tendentes a vigorizar la vida municipal y ampliar las fronteras del desarrollo regional en los años ochenta. Estos primeros impulsos transcurrieron entre la retórica y la normatividad, situación que termina por convertirse en la descentralización centralizadora experimentada en el periodo del presidente Carlos Salinas, sobre todo por la concentración asumida en función de cómo ejercer los recursos transferidos por el gobierno federal (Mizrahi, 2004). Sin embargo, ya que los procesos de descentralización suelen ser asimétricos, es posible destacar la amplia descentralización de la educación básica a partir de 1992, transferencia que afectó sensiblemente las relaciones intergubernamentales mexicanas (Gómez Álvarez, 2002). La apertura hacia los poderes territoriales mexicanos supuso un debilitamiento de las bases de apoyo del Partido Revolucionario Institucional (PRI) lo que, a la postre, llevaría al Partido Acción Nacional (PAN) a la presidencia de la República en el año 2000 con el triunfo de Vicente Fox.

Sin duda, comparado con 1982, los estados y municipios mexicanos gozan hoy día de mayores atribuciones, facultades y recursos para su desempeño. Sin embargo, México todavía es un país fuertemente centralizado. En comparación con otros países de América Latina, tanto el gasto como los ingresos públicos siguen muy concentrados en la federación en una proporción mayor que la de naciones unitarias (Díaz Cayeros, citado en Mizrahi, 2004: 137).

Para mediados de los setenta nadie hubiera apostado a una apertura del rígido poder central bipartidista de Venezuela, sobre todo porque se vivía un momento de bonanza petrolera que 
permitía oxigenar al sistema político dominante. Sin embargo, una década después, las propuestas para descentralizar el poder se colocaron en la agenda de la discusión para que, finalmente, se impusiera la tesis de la elección de los gobernadores de estado y la creación de la figura del alcalde y su elección, mandatarios territoriales que inician su legítima gestión en enero de 1990. En efecto, la reflexión venezolana incorporó -entre otros elementos- la necesidad de relegitimar el sistema político y la democracia que se encontraban en abierta crisis, la importancia de las reivindicaciones provinciales y sus movimientos sociales locales preteridas en el modelo centralizador y la búsqueda de la efectividad del Estado en su conjunto a través de políticas públicas sentidas como cercanas por el ciudadano de estados y municipios (Mascareño, 2000). Para ese momento, Venezuela transitaba una etapa de efervescencia de la sociedad civil, muy vinculada con los movimientos de base territorial. En este sentido, se afirmaba que la ampliación de los espacios democráticos sería posible a través de un ejercicio micropolítico propio del desarrollo local. De allí que "el nuevo localismo (que se vivía en el país), a través de múltiples y pequeñas redes de acción social que 'existen' en localidades: asociaciones de vecinos, grupos ecológicos, cooperativas, grupos de mujeres, organizaciones de cultura popular, asociaciones deportivas, etc., significarían el comienzo de una organización a escala humana, manejable, cercana, útil" (Salamanca, 1989: 464). Sin embargo -advierte el autor-, para que ello sea cierto es necesario generar una nueva cultura política que evite que las organizaciones se conviertan en grupos auxiliares de la acción del Estado o en organizaciones funcionales de los partidos y, por el contrario, puedan profundizar su carácter transformador de la relación Estado-sociedad.

El entusiasmo por descentralizar el poder del Estado también se hizo presente en países de corte unitario. Colombia, por ejemplo, avanzó hacia la descentralización en los ochenta, orientada sobre todo a la reforma del poder municipal. Sin embargo, poco tiempo después, la Constituyente de 1991 tendió a fortalecer el espacio provincial con un gobierno central jugando a la promoción del federalismo (Jaramillo, 1992). Con ello, Colombia lograría tempranamente uno de los más altos niveles de descentralización fiscal en América Latina (Cabrero Mendoza, 1996). Si bien se asumía que la reforma permitiría acercar el Estado a la sociedad civil, este cálculo estaba íntimamente relacionado con el encauzamiento de las protestas y movilizaciones locales y re- 
gionales desde los años setenta. En consecuencia, era indispensable su incorporación a los canales institucionales y, con ello, lograr tanto la modernización del Estado como la legitimación del sistema político.

Bolivia, república unitarista por historia y convicción, se planteó la reforma en cuestión. En su caso, el centro de la discusión fue promover la participación popular en los niveles locales y de la sociedad civil, proceso que se normó tardíamente en 1994 con la promulgación de la Ley de Participación Popular, cuyo impacto en la dinámica política es innegable (Molina, 1997a; Barbery, 1998).

Según Roy Rivera (2004), las propuestas de reestructuración en Centroamérica se presentaron como parte de los proyectos de modernización de los distintos países para mejorar los niveles de gobernabilidad e integración social. Allí, descentralización y participación fueron los pilares para constituir el Estado moderno y, con ello, dinamizar las instituciones públicas y los medios de gestión de lo público. Siendo Centroamérica una región que arrastra una larga historia de autoritarismo oligarca y exclusión, no es posible encontrar un sistema estructurado de actores intermediarios de la descentralización, por lo que las iniciativas son desacompasadas y de bajo consenso social. Con todo, afirma Rivera, dentro del juego geopolítico de la zona la descentralización constituye una suerte de ideología en toda América Central. Esta impresión la comparten Saldomando y Cardona (2005), quienes advierten que la descentralización centroamericana -a pesar de que su origen se vincula a los procesos revolucionarios y ello marca su naturaleza política y conflictiva- ha permeado en todos los países de la región en los últimos quince años, sobre todo ante la implantación de reformas constitucionales que reconocen su vigencia.

Como se observa, a pesar de las limitaciones de la reforma descentralizadora en América Latina, existe una expectativa esperanzadora sobre sus virtudes y alcances, sobre todo en lo que concierne tanto a la ampliación de las bases democráticas y su legitimación como a la rearticulación de la sociedad civil y el Estado en la vía de construir una nueva ciudadanía. Los años ochenta y noventa fueron tiempos en que se difundieron ideas alrededor de la descentralización como parte sustantiva de la reforma del Estado. No hubo país en el que no se abriera el debate -muchas veces intenso y conflictivo- sobre la necesidad de desagregar territorialmente el poder, aumentar la eficiencia del Estado o propiciar la participa- 
ción ciudadana, según fuera la perspectiva conceptual o ideológica de donde proviniera el discurso.

Las formas y los fondos de los procesos de descentralización en América Latina se nutrieron de las ideas de las diversas escuelas y enfoques que trataron de incidir en la reforma. Por una parte, las ideas liberales insistieron en el diseño institucional de la cuestión, donde prevalecieron las referidas al arreglo fiscal. Por su parte, tanto la perspectiva estructuralista como la marxista se orientaron hacia la arista política con énfasis en la participación (Von Haldenwang, 1990). En todo caso, el transcurrir del tiempo fue dibujando el verdadero comportamiento de la descentralización latinoamericana, proceso complejo, diverso, signado por avances y retrocesos, con características y resultados diferentes dependiendo del país que se analizara. En este sentido, se puede afirmar que la descentralización registró un perfil propio a partir de factores contingentes que determinaban las diferencias entre los países, como la asincronía temporal de los pactos políticos, la diversidad de grados de fiscalidad territorial, el nivel de transferencia de los servicios centrales, los tipos de cultura política, las ideas dominantes sobre la forma de Estado (más liberal-menos liberal), las modalidades de participación política, la diversidad de tipos de territorios intranacionales y de organización de ese territorio, el comportamiento de la presión de los grupos locales, el nivel de organización de la sociedad civil o la presencia empresarial en el desempeño de la descentralización.

El desarrollo de la descentralización latinoamericana ha estado enmarcado dentro de los límites que le imponen las posibilidades de la cultura política hispánica-centralizadora dominante, los rezagos de caudillismo y patrimonialismo, las crisis fiscal y social, la deslegitimación de los partidos políticos y de la política, así como el impacto en la economía territorial de las nuevas formas de producción y circulación de bienes y servicios en el ámbito global. Así, en medio de tal complejidad de factores, la relación Estado-sociedad -ahora redefinida al incorporarse la variable territorial en su comportamiento- ha evolucionado hacia formas múltiples de interacción entre la esfera de lo estatal y la esfera de lo civil. El desempeño de dicha relación luego de casi tres décadas de descentralización, es el tema del que nos ocuparemos en el siguiente apartado de este trabajo. 


\section{La relación entre el Estado descentralizado y la sociedad civil territorial latinoamericanos: bondades y limitaciones}

Han transcurrido casi tres décadas desde que las primeras discusiones sobre la crisis del Estado centralizado de América Latina cristalizaron en tímidas reformas para incorporar la visión territorial, sobre todo del ámbito local, ${ }^{2}$ en el manejo de los asuntos públicos. En cada uno de los países se narraba una historia republicana plena de personalismos, autocracias, dictaduras o militarismos que colocaba un dique cultural a la posibilidad de ampliar los espacios públicos civiles a partir de una nueva forma de Estado menos centralizado. A pesar de los antecedentes culturales, los países latinoamericanos -con sus indiscutibles diferencias- hoy pueden mostrar avances nada desdeñables en el cambio de la forma territorial del Estado a la vez que asoman un rostro inequívocamente diferente en lo que concierne a las formas y contenidos de las democracias. ¿Es posible hablar de cambios significativos y duraderos en la dirección de una nueva relación entre el Estado en su perspectiva descentralizada y las múltiples formas organizativas de la sociedad civil en su expresión territorial? Esta interrogante se discutirá en este apartado del artículo.

Para tal cometido, primero es conveniente reconocer la proliferación y consolidación de un número significativamente importante de organizaciones civiles de base territorial a lo largo de Latinoamérica, como un dato importante en el nuevo mapa sociopolítico. Al respecto, hacemos uso de una vieja propuesta de Albert Hirschman quien se apartó por un corto tiempo de su intenso trabajo conceptual y se dedicó -en unas vacaciones sabáticas en 1983- a recorrer un conjunto de experiencias de organización popular en América Latina. En una obra elaborada a partir de su recorrido de catorce semanas, el autor expresa su asombro por lo que encontró: en América Latina existía un complejo cuadro de desarrollo popular, el brote de un número importante de organizaciones intermedias que participaban en la ayuda a personas de menores recursos y, en función de ello, especula sobre los efectos sociales y políticos de lo que él denomi-

\footnotetext{
${ }^{2}$ En Colombia se introdujeron las primeras reformas en materia municipal en la década de los setenta. En Venezuela se aprobó la Ley Orgánica de Régimen Municipal en 1978, luego de un largo debate sobre su conveniencia. En el Chile de Pinochet se aprobaron reformas de reforzamiento municipal, en la perspectiva de una mayor eficiencia y eficacia, más no en la vía de la autonomía y la democratización.
} 
na "una densa red de esfuerzos por el desarrollo popular" (Hirschman, 1986: 116). Organizaciones relacionadas con la tierra, centros educativos urbanos y rurales, microempresas, academias de mujeres, cooperativas, promoción comunitaria cultural y deportiva, desarrollo de vivienda y desarrollo económico y social fueron vistas y analizadas en aquella incursión. A pesar de los avatares de los regímenes autoritarios, ese movimiento de base, mayoritariamente de corte territorial, pudo avanzar por causa de su naturaleza descentralizada y pluralista. Esta peculiaridad en la extensión de la sociedad civil territorial pudiera tratarse de "una corriente mundial, pues un movimiento similar parece estar desarrollándose en la India" (Hirschman, 1986: 116). En esa perspectiva, el autor refiere lo que Chandra Shekhar -político hindú en ascenso- pensaba al respecto de la proliferación de grupos sociales activistas en la India: "Las previsiones de la ciencia política dicen que hay miles de tales grupos que forman un movimiento descentralizado en lo que es una sociedad descentralizada. Afirman que el activismo social está ocupando el vacío dejado por la decadencia de otras instituciones políticas" (Hirschman, 1986: 116). Hirschman veía el nacimiento y desarrollo de un muy diverso esfuerzo local por reducir la distancia entre una gran masa poblacional latinoamericana respecto de lo que se tenían como derechos de todos y que representaba la fuente de enormes tensiones en el continente.

La crónica y análisis referidos se suscitaron en una época en la cual coincidían, como se dijo antes, tres fenómenos en América Latina: un movimiento hacia la democracia, otro hacia la consolidación de redes sociales -sobre todo locales- y una apertura hacia la descentralización del poder.

Casi un cuarto de siglo después de estos acontecimientos, la extensión y activismo de las organizaciones civiles -tanto de base territorial como organizaciones no gubernamentales (ONGS) dedicadas al desarrollo- forman parte del diagnóstico y estrategias en todos los países latinoamericanos. La Fundación Interamericana, tras evaluar sus programas luego de veinticinco años en América Latina, determinó que más de seis mil ongs en cuatro países (Ecuador, República Dominicana, Costa Rica, Uruguay), la mayoría de base local, incorporaron metodologías innovadoras para tratar de interactuar con el Estado. Al respecto, se destacó que "resulta especialmente interesante en esta época de democratización y descentralización el grado en que las organizaciones donatarias de la Fundación interactúan con los gobier- 
nos y otras entidades de la sociedad civil a nivel municipal y nacional" (Ritchey-Vance, 1996: 7).

Así, en toda la región es posible encontrar fenómenos de organización social -sobre todo de base local- como expresión de cambios sustantivos en la configuración ciudadana para acceder a los asuntos públicos. En este sentido es notable la proliferación de ofertas de espacios que pretenden articular al Estado con la sociedad civil, especialmente en los ámbitos territoriales de gobierno en una doble vertiente: desde la oferta del Estado y desde las propuestas de la sociedad civil. Este fenómeno representa lo que podemos denominar las bondades de esta dinámica. Por otro lado, sin embargo, persisten resabios y prácticas que frenan la incidencia de la acción de las organizaciones sociales en la profundización de las democracias latinoamericanas. Ésas son las limitaciones de la relación. En las páginas siguientes se ofrece un panorama general de estas realidades.

\subsection{Bondades de la relación: la expansión de espacios de articulación}

Es imposible dar cuenta de las innumerables formas de interacción entre las organizaciones civiles territoriales y las estructuras del Estado descentralizado, las cuales se pueden estimar en función del número de estados y municipios multiplicados por el total de sectores organizados que participan en estos niveles territoriales. Este ejercicio arroja una cantidad tal que, con toda seguridad, no existe un inventario exhaustivo de las relaciones en cuestión. Si nos referimos a la sociedad civil mexicana en general, por ejemplo, el estudio de los encuentros e interrelaciones entre los gobiernos y las formas de sociedad civil conducen a una complejidad tal que, ciertamente, "es posible incrementar ad infinitum la lista de actores, espacios y modos de interacción" (Olvera, 2003: 19). Ante esta realidad y de acuerdo con los propósitos del presente estudio, sólo comentamos un número muy limitado de esos espacios con la finalidad de mostrar sus principales características, tanto desde la perspectiva del Estado en su afán de crearlos como desde la posición de la sociedad civil en su búsqueda de autonomía. 


\subsubsection{La oferta desde el Estado}

En las últimas décadas Brasil ha obtenido renombre en materia de rearticulación entre el Estado y la sociedad, producto de dos realidades que sirven de modelo para otros países. Por una parte, el establecimiento de un marco regulatorio de tales relaciones y, por la otra, la introducción del presupuesto participativo como instrumento de democratización de las decisiones locales.

En el año 1999, el parlamento brasileño aprobó la Ley 9.790/ 99 que calificó a las personas jurídicas de derecho privado sin fines de lucro como Organizaciones de la Sociedad Civil de Interés Público (OSCIP), a partir de un consenso logrado entre organizaciones de la sociedad civil y los poderes ejecutivo federal y el legislativo. Esta iniciativa partió del Consejo de la Comunidad Solidaria ${ }^{3}$ en 1997, instancia que se propuso reformular el marco legal del Tercer Sector, como lo señala Elisabete Ferrarezi (2001). Llegar a este acuerdo fue producto de un largo camino recorrido en Brasil desde la década de los ochenta, cuando se inicia el debate sobre la reforma del Estado cuyos ejes eran la democratización, la equidad y la descentralización, siendo el principal reto superar el modelo de intervención estatal. Llevar a la práctica esta ley no ha sido fácil; representa un adelanto en la concepción del interés público y todavía no termina de ser asimilada tanto por el Estado como por la sociedad civil. En ello incide la larga tradición clientelar, patrimonial y corporativa presente en las políticas públicas.

En el ámbito local, el Presupuesto Participativo (PP) que promovió la prefectura municipal de Porto Alegre desde 1989, se ha convertido en una modalidad de gestión pública que funge como guía para muchos municipios de América Latina. El pp está asentado en una estructura y un proceso de participación de la población en función de tres principios básicos: reglas universales de participación; un método objetivo de definición de recursos de inversión y un proceso decisorio descentralizado (Fedozzi citado en Araujo, 2001: 241). El pp de Porto Alegre se reconoce como una experiencia de mayor participación de la población en los procesos de decisión. Por ello, siendo un instrumento que favorece la apropiación de la cosa pública por parte de los ciudadanos -a pesar de sus

\footnotetext{
${ }^{3}$ Este Consejo tenía los siguientes objetivos: diseñar e implantar programas innovadores en la asociación Estado-sociedad; desarrollar iniciativas para fortalecer a la sociedad civil y promover la interlocución política sobre temas estratégicos de desarrollo social.
} 
limitaciones y máculas-, el pp ha conferido alto grado de legitimación a las autoridades locales que lograron hasta el año 2000 el triunfo electoral en cuatro mandatos consecutivos.

Este caso es apenas una muestra de la proliferación de medios e instrumentos para la participación en al ámbito local, que desde el Estado o a través de acuerdos con la sociedad civil se han puesto en práctica en Latinoamérica. Audiencias públicas, cabildos abiertos, leyes de participación ciudadana, promoción del voluntariado, revocatorias de mandato y referéndums (Ziccardi, 1999; Spehar, 2001) son parte de la lista de instrumentos que se agregan a los presupuestos participativos para abrir la compuerta de la presión ciudadana en el ámbito territorial del Estado.

Una de las principales reformas para la participación ciudadana es la Ley de Participación Popular boliviana (LPP) de 1994. En atención a miles de organizaciones campesinas, indígenas y vecinales -extendidas por toda la geografía del país-, la Ley les confirió personería jurídica de base, creando las llamadas Organizaciones Territoriales de Base (отв). Se trataba, según José Carlos Campero y George Gray (2000), de saldar una deuda histórica del Estado boliviano con la población crecientemente organizada y con mayor capacidad de presión. En el ámbito municipal, la Ley de Participación boliviana ha incentivado la conformación de diferentes espacios de articulación de la sociedad civil con el Estado. Los Comités de Vigilancia de la gestión pública, por ejemplo, funcionan como un instrumento de apoyo a las отв. A su vez, al instituirse la planificación municipal participativa, se han elaborado planes tanto operativos como de desarrollo municipal bajo la regla de la participación en su elaboración (Thevoz y Velasco, 1998; Molina, 1997a; Molina, 1997b; Barbery, 1998; Verdesoto, 1998). Philip Oxhorn (2001) cataloga este notable esfuerzo de reforma como una ambiciosa tarea en el plano de la participación ciudadana. Tal adjetivación se refiere tanto a la instauración de gobiernos locales (311) inexistentes antes de la Ley, como a la legalización de más de 16000 отв para 1997. "De un solo golpe, la LPP ofrecía soluciones institucionales para empezar a atender los numerosos problemas que aquejaban a Bolivia, desde la fortaleza del Estado y la penetración territorial hasta la construcción de una sociedad multiétnica" (Ibidem: 8).

Colombia, con una dilatada tradición municipalista, también muestra una amplia gama de medios para articular a la sociedad con el Estado. En Cali y Armenia, por ejemplo, los gobiernos locales se afianzan en la formulación de políticas públicas socia- 
les dentro de una perspectiva de descentralización de las decisiones (Varela, 2000). De igual manera, el plan local de desarrollo participativo es de cumplimiento obligatorio en los gobiernos locales colombianos, en función de la instrumentación de talleres temáticos participativos, además de que la Ley 134 establece mecanismos de consulta popular como los cabildos abiertos, los consejos de planeación, las juntas de educación o los comités de control de los servicios públicos (Betancourt, 2001; Londoño, 1998).

En el ámbito de los gobiernos intermedios (provinciales, estatales y departamentales), también es posible señalar un conjunto amplio de medios de articulación. En Argentina, país con tradición federal, la provincia de Mendoza utiliza los consejos sociales departamentales como vía para la concertación. Sectorialmente es posible encontrar comunidades de usuarios de agua que participan en las inspecciones de cauces y en la administración de la red de irrigación. En esta provincia la Ley 23696 reconoció la presencia activa de individuos y sociedad en los asuntos públicos como una vía para profundizar la reforma de gestión pública (Quesada y Cuello, 1999; Magnani, 1992; Arroyo, 1997). En Córdoba, la acción de las ONG se reconoce como parte fundamental de la gestión pública. Así, existen instituciones de democracia semidirecta como la iniciativa popular, las consultas, la revocatoria o el referéndum. De igual manera, el Consejo Económico y Social de la provincia actúa junto con las mesas de concertación como canales de control social sobre las instancias de poder (Rey, 1992; López, 1997; Carrizo, 1997).

México ha instituido medios de participación en las entidades federales y en los gobiernos locales. Es importante recordar cómo la movilización de la sociedad civil mexicana en los años ochenta y noventa, en particular la territorial, incidió en la caída del autoritario régimen del PRI, con lo cual se creaban expectativas para cambiar profundamente las relaciones Estado-sociedad. Esas luchas permitieron -según Alberto Olvera (2003)- que las élites surgidas de la sociedad civil accedieran a los gobiernos municipales y estatales, trasladándose a este campo liderazgos e iniciativas de cambio. En ese contexto, en el estado de Chihuahua, a partir de la descentralización del sistema educativo, se crearon espacios de reflexión y discusión de propuestas de las agendas educativas con la sociedad civil, a partir de lo cual se inicia un proceso de autonomización de las unidades educativas con la presencia de los grupos civiles organizados de la entidad (Cavo, 1998). Por su parte, en el estado de Baja California, los conve- 
nios de desarrollo social, junto con los consejos agropecuarios, la comisión para la promoción de las exportaciones o el Fondo de Financiamiento de las Empresas de Solidaridad, son expresiones de medios de articulación, desde la oferta del Estado, entre sociedad territorial y Estado (Mercado y Olmos, 1997). De manera particular, en el estado de Morelos fue posible ver importantes cambios políticos en los cuales se redefinió la relación entre la sociedad civil de esa entidad y la construcción de gobernabilidad territorial, que culminó con la instauración de un gobierno del PAN y la propuesta de nuevos espacios de encuentro Estado-sociedad por parte de los nuevos gobernantes (Quero, 2003). En el ámbito urbano-local, el estudio sostenido por Cabrero Mendoza (2005), a lo largo de diez años continuos en varios municipios mexicanos, ${ }^{4}$ muestra el desarrollo y consolidación de espacios de acción pública en los cuales la trama de relaciones entre la sociedad civil territorial y el Estado cuenta con una oferta que, en su mayoría, proviene de las estructuras de gobierno y que se transforman en incentivos para la inserción de actores sociales locales.

En Centroamérica, por su parte, se han creado una cantidad notable de formas de articulación Estado-sociedad local. Los consejos escolares directivos en Nicaragua (Rivarola y Fuller, 1998), los consejos locales en República Dominicana (Calderón, 2001), los consejos locales de desarrollo en Guatemala (Saldomando y Cardona, 2005) o la propuesta de Contraloría Ciudadana en el ámbito local en El Salvador (Cummings, 2002) representan apenas algunos ejemplos de diversos esfuerzos en la dirección de revalorar la dimensión territorial como espacio para ensayar el acercamiento entre la sociedad organizada y las estructuras de gobiernos descentralizados en esta región latinoamericana.

Perú reinició su camino a la descentralización en el año 2002 con la elección de los presidentes regionales y la promulgación de la Ley de Bases de la Descentralización, seguidas de la Ley que norma los gobiernos regionales y, en el 2003, la aprobación de la Ley de Municipalidades. Se trató efectivamente de un relanzamiento político entusiasta que permitió -negociación y presión de la sociedad civil de por medio- aprobar las figuras de los consejos de participación regional y de los consejos de participación municipal (Mascareño 2005a). En ambos casos, la sociedad civil territorial posee presencia activa en la deliberación e inci-

${ }^{4}$ Toluca, León, Aguascalientes y San Luis Potosí. 
dencia sobre las políticas y decisiones de cada nivel de gobierno. Para observar su cumplimiento, el Grupo Propuesta Ciudadana (2003, 2004), consorcio que reúne once ONGs peruanas de gran peso en la vida nacional y regional, mantiene un programa de vigilancia y control ciudadano sobre la gestión regional. El propósito de este ambicioso programa es que la participación ciudadana en el ámbito territorial se convierta "en un mecanismo imprescindible para construir condiciones de gobernabilidad regional y local" (Azpur, 2003: 3).

En cada país, en cada provincia o en cada municipio latinoamericano es posible encontrar hoy día alguna expresión de oferta estatal para la incorporación de grupos civiles organizados en la gestión descentralizada. Independientemente de las limitaciones y resabios que se hacen presentes cuando se formula la propuesta de participación desde los aparatos de gobiernos, es necesario aceptar que algo está pasando, algún tipo de apertura ha ocurrido en las últimas décadas. Como todos sabemos, no se trata de una oferta gratuita ni voluntaria. Existe otra cara de la moneda que hace posible, de manera unívoca, que tales espacios tomen su lugar en la trama institucional y puedan avanzar más allá de las estrechas paredes del Estado.

\subsubsection{Los espacios de participación desde la sociedad civil}

territorial: la otra cara de la moneda

La Organización Panamericana de la Salud (OPS) -en el documento promocional de sus 100 años- establece con claridad que los espacios de participación para enfrentar los problemas de salud locales y definir las respectivas políticas públicas, no pertenecen sólo al gobierno local sino, sobre todo, a las comunidades y sus respectivos intereses. De allí que el documento elaborado para tales efectos lo hayan denominado "Municipios y comunidades saludables" (ops, 2002) y no como años antes, cuando se hacía referencia sólo al municipio. Es un cambio lento pero visible. Por ello, se reconoce la existencia de una tendencia global hacia la descentralización de las políticas sociales, con un papel preponderante en el liderazgo de las autoridades locales pero con la corresponsabilidad de todos los ciudadanos y sus familias (Alleyne citado en oPs, 2002: IV). ¿Dónde comienza y dónde termina el espacio del Estado descentralizado y la sociedad territorial en las políticas sociales? No hay una respuesta satisfactoria, como no sea la de la construcción de espacios de 
corresponsabilidad. Pero, de nuevo, surge otra interrogante, ¿cuándo comienza a perderse la autonomía de las organizaciones civiles en virtud de la mayor fortaleza del Estado a la hora de la negociación? Tampoco existe un límite claro que no se defienda con la idea de que la sociedad civil debe continuar avanzando en su nivel ciudadano para advertir y sortear los peligros que ello encierra.

Como explican Adriana Rofman y Marisa Fournier (2004), la expansión de programas de desarrollo local no se explica solamente como un efecto discursivo o producto de la difusión de las innovaciones. Este fenómeno refleja una redefinición en las formas y contenidos de la intervención social que hace que, finalmente, las organizaciones civiles -sean sociales o empresariales- se apropien de la dinámica del desarrollo local. Allí comienza a percibirse un cambio sustantivo en la direccionalidad de la oferta que ya no sólo pertenece al Estado o a los gobiernos, sino que comienza a fluir desde los espacios ciudadanos. Las experiencias de promoción del desarrollo local que se registran actualmente en la zona conurbana noroeste de Buenos Aires, muestran cómo las iniciativas de articulación entre los actores estatales y civiles no provienen sólo del aparato gubernamental ni tampoco, de manera exclusiva, del terreno de lo civil. El trabajo conjunto del municipio Moreno, la Universidad Nacional Gral. Sarmiento y la experiencia comunitaria de los Aguante de la Cultura, hace pensar en una perspectiva diferente del problema. En ese sentido, una conclusión importante es que, para los efectos de la rearticulación Estado-sociedad vista territorialmente, "no es posible señalar previamente cómo debería conformarse la instancia de articulación local que lidere el proceso. La constitución de este espacio, y la identificación de los actores que lo conforman forma parte del mismo proceso de cambio [negritas en el texto], y estas experiencias resaltan que cabe aportar a este proceso desde distintos ámbitos institucionales: académico, de gobierno y organizaciones sociales" (Rofman y Fournier, 2004: 217).

Meses antes de que se promulgara la Ley de Bases de la Descentralización de Perú, la Red Perú llevó a efecto su v Encuentro Nacional, en abril de 2002. Con la presencia de 160 representantes de experiencias de concertación provenientes de 14 regiones peruanas, el encuentro se desarrolló bajo el lema "Construyendo la gobernabilidad democrática desde los espacios regionales y locales" (Red Perú, 2002). La sociedad civil reunida en este foro se propuso objetivos muy concretos: la instituciona- 
lización de la Red y de los espacios de concertación regional y local, la incorporación de los planes concertados de desarrollo y los presupuestos participativos, así como la promoción de mecanismos de vigilancia ciudadana. En buena medida, aquellas propuestas se recogieron posteriormente en la Ley de descentralización, la de los Gobiernos Regionales y la Ley de Municipalidades. Este tipo de propuestas provenientes de los espacios civiles parten de diagnósticos que esclarecen la futura acción para incidir en las políticas públicas del Estado, en especial en la de descentralización. Para Red Perú era claro que "uno de los problemas más importantes es la falta de identidad institucional, porque quienes tienen la capacidad de decisión no siempre participan en los procesos de concertación. Por un lado, existe desconocimiento acerca del proceso y los objetivos de la descentralización y, por el otro, no ha sido bien definido el rol que deben cumplir los espacios de concertación en este proceso" (Red Perú, 2002: 89).

Como señala Adriana Clemente (2000), la década de los noventa fue escenario de permanentes conflictos en la relación Estado-sociedad, envueltos en una búsqueda de nuevos consensos y medios para lograr una mayor gobernabilidad con las organizaciones de la sociedad civil. Esta difícil dinámica permitió una suerte de reconversión de la gestión local que concitó múltiples articulaciones y procesos de mutua influencia. En este marco, el Programa FICONG, ${ }^{5}$ ejecutado entre 1991-1998, fue escenario de un conjunto denso de experiencias de incidencia desde la sociedad civil territorial en las respectivas políticas públicas. En la publicación hecha especialmente para difundir los resultados ${ }^{6}$ es posible encontrar experiencias como las que se reseñan a continuación. La concertación entre la cooperativa de intermediación financiera (Cofac), el Centro Latinoamericano de Economía Humana (CLAEH), el Centro Cooperativo Uruguayo (CCU) y el departamento de extensión de la Universidad de la República permitió el desarrollo de una experiencia que durante dos años se ejecutó en el departamento de Colonia, Uruguay. Si bien es complejo el proceso para concretar las iniciativas de desarrollo, sobre todo por los largos tiempos de aprendizaje y la demanda de recursos de sostenimiento que ellas suponen, la aparición de al-

\footnotetext{
${ }^{5}$ Programa de Fortalecimiento Institucional y Capacitación de Organizaciones no Gubernamentales para América Latina, ejecutado por el Instituto Internacional de Medio Ambiente y Desarrollo, IIED-América Latina, con sede en Buenos Aires.

${ }^{6}$ Revista Pobreza Urbana y Desarrollo, "Planes y programas participativos para el desarrollo local”, año 9, 20, abril de 2000, Buenos Aires.
} 
gunos resultados en ámbitos familiares para los actores locales hace que surja una nueva forma de hacer las cosas, aceptando que los procesos de desarrollo local son exigentes tanto en recursos como en conocimiento (Marsiglia, 2000: 55-61). Como se sabe, la experiencia de Villa El Salvador, en Lima, representa un paradigma de iniciativa ciudadana local en busca de una mejor articulación con el gobierno local. Surgida en 1971, La Villa es hoy una ciudad popular dentro de una gran metrópoli, con más de trescientos mil habitantes y un tejido social complejo y organizado. La experiencia de este mundo urbano limeño ha implicado que el plan de desarrollo se convierta en el plan de todos y no en algo que ejecuta la municipalidad (Llona y Zolezzi, 2000: 18-22).

Este tipo de oferta desde la sociedad civil para el desarrollo local abunda en América Latina, sobre todo dirigidas desde ongs que han incursionado en el ámbito de acción social. Y así se entiende en tanto que potenciar la vida local con mayor participación y representación supone "un estilo de gobernar diferente y [...] un desarrollo de la tarea educadora de la ciudadanía local y de su cultura cívica" (Friedmann y Llorens, 2000: 4). No cabe duda de que, entendiendo la descentralización como una institucionalidad que potencia la concertación de los actores, su viabilidad se dará por el grado de confianza mutua entre los órganos representativos del Estado y los representantes civiles. Es una doble búsqueda tanto por el lado político como por el económico y social (Göske, 1999). En lo social, la búsqueda se orienta hacia la autonomía de la actuación de las organizaciones civiles como parte activa de la gestión de lo público. En lo económico, no cabe duda de que la relación entre empresarios y autoridades locales exige una redefinición que apunte hacia la cooperación público-privada (Hengstenberg, 1999). Más que un conflicto entre polos irreconciliables, el desarrollo territorial descentralizado como marco para una rearticulación Estado-sociedad supone la creación de espacios concertados entre actores sociales públicos y privados, así como a una nueva institucionalidad que responda a la modernización de los ámbitos productivos locales (Alburquerque, 1999).

Son indudables los avances en la construcción de espacios públicos de rearticulación del Estado descentralizado y la sociedad civil en los territorios subnacionales. Sin embargo, persiste un alto de grado de reserva respecto de los resultados obtenidos tanto en la satisfacción ciudadana como en los esperados apor- 
tes al desarrollo y consolidación de las democracias latinoamericanas. En este sentido, en consecuencia, es necesario plantearse la siguiente interrogante: ¿cuáles son las limitaciones que dificultan el logro de un cambio sustantivo en la calidad de esa articulación Estado-sociedad en América Latina, tanto por la vía de la democratización como de la descentralización? Intentaremos algunas aproximaciones en el siguiente apartado.

\subsection{Limitaciones en la relación Estado descentralizado- sociedad territorial}

En las últimas tres décadas, en América Latina ha surgido una profusión de ideas sobre la rearticulación del Estado con la sociedad en busca de horizontes de democracia y ciudadanía. En ellas, la descentralización del poder ha sido la invitada de honor al lado de la democratización del continente. En este mismo lapso, Latinoamérica ha visto aparecer y desarrollar un número impresionante de organizaciones civiles que, con sus virtudes y perversiones, se han instalado en la agenda de los asuntos públicos. Ambas realidades son loables, sin embargo, persisten aspectos propios del secular estadocentrismo latinoamericano, asociado con un patrón cultural patrimonialista que devino en relaciones clientelares entre quienes detentan el poder del Estado y la sociedad que pugna por hacerse de un espacio de autonomía. Esta huella perenne introduce severas limitaciones a los intentos de creación de nuevos espacios públicos democráticos. Algunas de sus limitaciones se analizan a continuación.

\subsection{1 ¿Incide la relación Estado descentralizado-sociedad territo-} rial en el mejoramiento de las democracias latinoamericanas?

Esta pregunta se puede reformular de la siguiente manera: cexistirá una influencia de la descentralización sobre los grados de democracia y, particularmente, sobre la posibilidad de auspiciar relaciones Estado-sociedad más democráticas? Dentro del espacio democrático, asumiendo que existen varios grados de calidad democrática en América Latina, la respuesta no resulta automática. Algunos estudios recientes (Giannoni, 2004) recomiendan precaución por las siguientes razones: a) no existe una fuente definitiva que ofrezca un marco conceptual que permita afirmar acerca de la relación directa entre descentralización y democracia, pues la primera se asumió como producto de una 
mala práctica del centralismo pero no necesariamente reduce la tiranía de los líderes y tampoco aumenta el control de los ciudadanos sobre las élites gobernantes; $b$ ) los resultados empíricos de esta relación en 18 países latinoamericanos (donde la hipótesis era: a mayor descentralización, mayor fortaleza democrática) muestra que en la mayoría de los países, la relación ha sido inversa. Por ejemplo, Argentina -a pesar de su grado de federación- no ha conducido a un buen sistema de representación ni al logro de un mejor balance del poder. En Costa Rica, por el contrario, aun con su alto grado de centralismo, la democracia permanece como una de las de mayor eficacia en el continente. En contraparte, Ryan (en Gianonni, 2004) advierte que un mayor grado de descentralización en Costa Rica podría tener un efecto desestabilizador sobre la democracia y c) la descentralización es una buena política pero no hay que esperar que ella, por sí sola, resuelva los problemas de desbalance de poder, las resistencias de las culturas políticas patrimonial-clientelares de los líderes locales ni la real efectividad de los gobiernos por la vía de la participación ciudadana, toda vez que ésta en sí misma no crea un gobierno efectivo.

Un factor que determina la mayor o menor incidencia en los procesos democráticos es la supeditación de los territorios al poder de los líderes centrales cuando ocurren procesos de recentralización del poder una vez que un país alcanzó niveles de descentralización. Este aspecto ha estado presente en los últimos tiempos. En los casos de Brasil y Argentina, Kent Eaton y J. Tyler (2004) advierten que la recentralización comenzó a posicionarse como parte de la agenda política, sobre todo por el pronunciado protagonismo presidencial que intenta revertir las reformas que propiciaron la autonomía de los gobiernos subnacionales y que determina la pugna por el control de los recursos fiscales. En Venezuela, el gobierno de Hugo Chávez ha dado muestras evidentes de una vocación recentralizadora tanto por el control de las transferencias como por el ataque constante a las autonomías de las entidades federales y, además, del municipio como nivel de gobierno (Mascareño 2005b). El caso colombiano llama la atención -sobre todo porque muestra que sí es posible revertir la descentralización- dentro de situaciones contingentes que conduzcan hacia ese destino. Efectivamente, ya que Colombia es el país que ha alcanzado uno de los mayores grados de descentralización de América Latina, hoy se hacen presentes medidas que atentan contra esos logros. Las políticas gubernamentales 
en ese sentido son producto de la presión del déficit fiscal, de la pobreza creciente que demanda soluciones, del conflicto armado que requiere medidas centralizadoras y la presión de los organismos multilaterales (Velásquez, 2004). Si la dominación del poder se inclina hacia una mayor centralización, en esa medida la relación entre la sociedad civil territorial y las estructuras de gobierno descentralizadas sufrirán una inexorable mediatización y debilitamiento, ya que las organizaciones dirigirán su interés hacia la oferta que provenga de las agencias centrales.

En definitiva, la contingencia a la que se encuentran sometidas las relaciones en estudio determina, en buena medida, sus posibilidades de contribución a los procesos democráticos. En la medida en que los territorios adquieren niveles de autonomía que facilitan la consolidación de espacios públicos, el aprendizaje de la sociedad civil territorial incrementa la probabilidad de mejoramiento democrático. En caso contrario, los liderazgos centrales mantienen su perfil tradicional de élites autoritarias en permanente ejercicio de control sobre la sociedad civil.

\subsubsection{Los limites que impone la cultura patrimonial y clientelar}

Existe una vieja pero muy actual tensión entre las formas de dominación tradicional y la racionalización moderna del poder. Max Weber (1992) estableció con claridad que la dominación patrimonial es aquélla orientada sobre todo por la tradición y ejercida en virtud de un derecho que se asume como propio. Dentro de esta tradición, la administración se la apropia quien ejerce la dominación, operando sobre la naturaleza de la economía y, en particular, de la economía fiscal, impidiendo la preeminencia de reglas legales racionales. Precisamente por eso, el patrimonialismo se opone al establecimiento de relaciones impersonales donde reinaría la dominación racional, que descansa en la legalidad de ordenaciones estatuidas.

No existen sociedades donde imperen modelos puros de patrimonialismo o de dominación racional. Sin embargo, en la modernidad la lucha por la secularización del poder ha sido la marcha de las sociedades modernas hacia formas menos patrimoniales y más impersonales en su ejercicio.

Por su parte, la permanencia de la relación clientelar representa un viejo problema en sociedades con aspiraciones igualitarias: se trata de la persistencia bajo distintas formas del homo 
hierarchicus. En una perspectiva que va más allá del inmediatismo sociologista, afirma José González (1997), el clientelismo social constituye un universal antropológico, lo que no debe confundirse con la naturalidad del clientelismo. Si así fuera, la historia social de la humanidad no hubiera podido trascender los límites de lo estático constituido y, a partir de la tensión moral del hombre por construir mundos ideales, no hubieran sido posibles la modernidad y la democracia contemporánea. En la vigencia del clientelismo político, González observa la confluencia de varios vectores: su vínculo con el intercambio de bienes; su relación con el parentesco y el territorio; un ethos nucleado alrededor del honor y el intercambio simbólico como basamento ideológico; su constitución en la vida política municipal y su vínculo con el Estado nacional a través de los partidos y la burocracia. Como en todos los clientelismos, en consecuencia, prima el horizonte pragmático sobre el normativo (Ibidem).

Para el caso latinoamericano, el estudio de la cultura política cobra indudable valor ya que la misma se caracteriza precisamente como clientelar, patrimonial y, en consecuencia, poco proclive al civilismo y sus valores. $\mathrm{Y}$ es necesario insistir en el tema cuando se habla de descentralización porque, como se dijo, una de las esperanzas puestas sobre ella era la posibilidad de constituirse en medio para un mayor accountability y, con ello, lograr una gestión más transparente de cara al ciudadano.

Ese ideal social se encuentra en entredicho a la luz de las realidades políticas latinoamericanas en las cuales, ante la fragmentación de las organizaciones populares y sociales (la mayoría de ellas de corte localista o de ámbito territorial), el poder real lo asumen las élites que se convierten en actores dirigentes de la sociedad civil (Quero, 2004). Éstas, por su mayor capacidad de negociación, terminan siendo depositarias del discurso democrático que se pretende desde el espacio civil, para repetir -de manera consuetudinaria- la dependencia clientelar que culmina por excluir a las organizaciones civiles de la esfera de la influencia en las decisiones públicas. En este sentido, el neopluralismo latinoamericano -como afirma Oxhorn (2003) - tiende más bien a fragmentar y atomizar a la sociedad civil, sobre todo porque los líderes públicos, una vez electos, poco o nada se someten a la inspección sobre su poder. Ante esta perspectiva, las identidades grupales y los intereses colectivos pierden su valor intrínseco y adoptan decisiones individuales y de interés propio. Así, "la descentralización de los servicios de bienestar social [...] pueden 
fragmentar aún más a potenciales movimientos sociales populares, restringiendo la actividad organizativa del sector popular a comunidades bastante limitadas" (Ibidem: 153).

Esta dinámica encierra riesgos mayores. Como afirma Norbert Lechner (1992), una de las principales demandas hacia la política moderna y que la democracia no puede ignorar, es la pertenencia a una comunidad, búsqueda que se torna más angustiante a medida que la fragmentación de espacios y tiempos diluye las identidades colectivas. Allí, cuando el sentimiento de desamparo domina la escena, las mayorías terminan prefiriendo el refugio en certezas absolutas e identidades cerradas. Ante una realidad imponente, surge un dilema: o el Estado se reforma de manera tal que restaure una nueva noción de comunidad o, en su defecto, las sociedades latinoamericanas terminarán bajo el cobijo de movimientos populistas o fundamentalistas. Esta misma advertencia la formuló recientemente Pierre Rosanvallon (2006) cuando, al hablar de los peligros y limitaciones de las actuales democracias, insiste en la necesidad de construir la Comunidad Política como uno de los posibles antídotos contra los rezagos y resurgimientos patrimoniales en el uso del poder del Estado. Por ello, insiste, la Política no puede quedar reducida a una gestión de los problemas cotidianos (que es la tendencia con los procesos de descentralización) porque, en definitiva, la Política no puede ser una gestión de copropietarios en la cual la Democracia participativa queda reducida a la administración de esos problemas diarios y nos olvidamos de la recreación de la Comunidad de intereses.

En este momento del análisis es conveniente introducir la siguiente pregunta de Douglas Chalmers (2001): ¿Qué tipo de instituciones que conectan a la sociedad civil con el Estado fomentan los valores democráticos? Además de las instituciones constitucionales liberales, tradicionalmente -como ya se apuntó- han sido el clientelismo, el corporativismo y el partidismo las formas de intermediación dominantes en la relación Estado-sociedad civil. Cuando éstas se han debilitado (que es el caso de América Latina), el patrón de instituciones de intermediación se torna más abierto, buscando un cierto grado de autonomía y fluidez. Por ello, existió la época, dice Chalmers, en la que las organizaciones de base y no gubernamentales se consideraron la solución a los problemas que generaba el Estado centralizado, por lo cual el concepto de capital social se convirtió en medida de éxito y en consigna de moda. Pero, ¿hasta dónde los regímenes abiertos son más democráticos? Este régimen, bajo determina- 
das circunstancias, puede ser elitista, no igualitario. En América Latina, por su parte, se instaló un fuerte sentimiento de que la sociedad civil pudo haber desempeñado un importante rol en la democratización pero, a su vez, esta sociedad civil no tiene espacio en un Estado ordenado porque sus características de ciudadanía y trabajo voluntario no forman parte de la cultura latina. Como lo señala Pranab Bardhan (2002) al estudiar el federalismo fiscal, las culturas predominantes en los países con menor nivel de desarrollo exigen una revisión de los incentivos que encierran las reformas que pretenden implantarse, la mayoría de ellas pensadas desde y para culturas de países desarrollados.

Así, referimos nuevamente otra pregunta de Lechner (2000), ¿Cómo debería ser una política no dirigista que enfrente la orientación clientelar y populista desde el poder central y los caciques locales en América Latina? No hay respuestas directas. En consecuencia, ya que la descentralización es una vía de acción colectiva, ¿tendrá la capacidad para realizar aportes a la transformación del capital social en acción ciudadana?

\subsubsection{Los límites de la participación}

A pesar de que poseen una realidad de Estados unitarios fuertemente centralizados, los países centroamericanos han avanzado desde los años ochenta -dentro de sus determinantes históricopolíticas y las limitaciones propias de una zona de alta conflictividad y desestabilización institucional- hacia formas descentralizadas del poder con base en el ámbito municipal de gobierno. Este camino ha sido, sin duda, convergente con la democratización de esta subregión latinoamericana, al cual la ciudadanía le ha apostado mayoritariamente. En esa apuesta, los ciudadanos le otorgan una alta valoración a la participación ciudadana. Sin embargo, a pesar de la proliferación de mecanismos que crean espacios para la participación, se registra un notable contraste con los bajos niveles de participación real (Saldomando y Cardona, 2005).

Colombia es uno de los países latinoamericanos con mayor profusión de medios e instancias para la participación ciudadana, sobre todo luego de la Constituyente de 1991. En virtud de ello, los ciudadanos colombianos han reclamado de manera creciente su presencia en el manejo de las políticas públicas. Sin embargo, advierte Darío Restrepo (2003), es notable la carencia de una sistematización analítica acerca del verdadero alcance de 
aquella participación y, por el contrario, se han entronizado discursos ideológicos sobre la democracia participativa, el establecimiento de normas, programas y medios en la esfera estatal y proliferan manuales de adiestramiento para el logro de una buena participación.

Efectivamente, la participación como acto que busca redimir a la sociedad de las deficiencias de la representación política, cuyas vituperadas instituciones son casi condenadas al papel de jarrones chinos cuando no al rincón de los recuerdos en las democracias latinoamericanas, ha tomado su lugar en la conciencia colectiva de nuestras sociedades.

La popularidad de la democracia participativa -evidente, incesante y creciente- termina vinculada al malestar ciudadano con la democracia representativa. Así, cada crítica a la representación se espera resolver con la democracia participativa. Se trata, como lo define Restrepo (2001), de enfrentar un prontuario antirrepresentación sin percatarse de que la opción de participación también posee un límite para resolver las desigualdades sociales y, lo más grave, en nombre de ella (la participación) se fortalecen procesos de fragmentación que atentan contra la posibilidad de crear referentes comunes y colectivos. Se trataría, en la versión de Lechner (2000), de disminuir las posibilidades para recrear una comunidad política que enfrente la siempre ventajosa presencia (por su mayor probabilidad de conexión subjetiva con las preteridas expectativas de la población latinoamericana) de los movimientos populistas y fundamentalistas.

Si bien la descentralización se ha legitimado en el discurso de la participación, es en esta materia donde claramente se observan debilidades en tres sentidos: la vigencia del centralismo y la cultura de relaciones verticales, la fragmentación del tejido social luego de los autoritarismos y las fallas de la reforma misma que, en la práctica, deja de lado la participación. De allí que, en la inmensa mayoría de las ciudades latinoamericanas, los procesos de participación son de poco impacto y, la más de las veces, de carácter consultivo (Gallicchio y Camejo, 2005).

Luego de tres décadas de discurso de participación, buena parte del cual se ha asociado a la descentralización del poder en América Latina, las certezas que éste ofrecía se han diluido y las limitaciones y perversiones de las prácticas de participación salen a flote. Es necesario, entonces, repensar la noción de lo público y recuperarlo como un asunto de la sociedad y no sólo como un espacio de realización del Estado, sugiere Nuria Cunill (1997). 
En esa perspectiva, la participación ciudadana en tanto que reclamo de libertad e igualdad de los sujetos sociales para lograr su presencia en la acción pública, supone construir una ciudadanía que, en tanto entidad política, "no se resuelve automáticamente en el establecimiento de oportunidades para la participación en deliberaciones democráticas y en la toma de decisiones públicoestatales, ni queda restringido a su ámbito. Supone, sí, un contexto institucional que realice el principio de autonomía, permitiendo a la vez el ejercicio de la ciudadanía en relación con la subjetividad" (Cunill, 1997: 144). En ese sentido, ya que la autonomía es un principio fundamental para la ciudadanía, "la concreción de las condiciones para la aplicación de este principio equivale a la concreción de las condiciones para la participación de los ciudadanos en las decisiones sobre cuestiones que son importantes para ellos" (Held citado en ibidem: 145).

A sabiendas, como advierte Cunill, de que la publificación de la administración pública trasciende lo mero organizacional y se inserta en el vigor de lo institucional y, sobre todo, de lo político, con lo cual se trataría de publificar al Estado en la búsqueda de un modelo de gobernabilidad democrática, ¿cómo se comportan en la práctica los procesos de participación ciudadana en América Latina? Busquemos una aproximación a algunas respuestas por la vía del análisis de dos casos emblemáticos: el presupuesto participativo brasileño y la Participación Popular de Bolivia.

Como lo analizan Elvia Cavalcanti y Reynaldo Maia (2000), la innovadora propuesta de presupuesto participativo amparada en la Constitución brasileña de 1988, se ha difundido como una alternativa a los modelos tradicionales de gestión de ciudades, con la cual se espera establecer nuevos patrones de articulación entre los intereses organizados y el Estado y, con ello, alcanzar nuevas condiciones de gobernabilidad y governance local. Si bien se acepta que esta técnica de gestión posee indudables aspectos positivos y que supone un salto respecto de las modalidades convencionales de relaciones con la sociedad local, existen limitaciones y perversiones que es necesario señalar. En primer término, quienes han impulsado su uso, en este caso el Partido de los Trabajadores de Brasil y sus liderazgos municipales, han terminado revistiendo a esta técnica de consulta con virtudes trascendentes como sería la profundización de la democracia; con ello, se aspira a reforzar la vía de la democracia participativa que superaría a la democracia representativa. De esta manera, quienes lo propugnan logran dos resultados perversos: el proceso de con- 
sulta se convierte en un medio de legitimación del liderazgo que lo dirige y, a la vez, al presentarse como la expresión más legítima de la voluntad general en manos del ejecutivo, se promueve el desgaste del parlamento local ${ }^{7}$ como el locus de la democracia liberal en el que se forja, legítimamente, la voluntad popular (Cavalcanti y Maia, 2000). En definitiva, se crea un clima de confrontación entre el Consejo del Presupuesto Participativo y la Cámara de ediles, con la consecuente superposición de las atribuciones de ambos espacios de decisión (Araujo, 2001). En segundo lugar, ya que la movilización poblacional se estimula con fines de democracia directa y no de control y presión sobre la representación constituida, se oxigena la dictadura de las minorías activas, una de las imperfecciones de la democracia liberal (Dahl citado en ibidem: 150). En tercer lugar, el mecanismo de participación corre el riesgo de incentivar el uso de las tácticas de cooptación de los liderazgos comunitarios, siendo un campo fértil para el amiguismo al imponerse la lógica del intercambio de favores para el mantenimiento del poder del voto. En ese sentido, las instancias del presupuesto participativo, al constituirse en los espacios que legitiman las reivindicaciones sociales en materia de equipamientos y programas sociales, terminan asfixiando la dimensión contestataria de los movimientos sociales y compromete el principio de autonomía de las organizaciones civiles (Araujo, 2001). Finalmente, advierten Cavalcanti y Maia, es necesario reconocer la verdadera dimensión de este mecanismo de participación: se trata de un reparto de recursos limitados que, aunque necesarios, se alejan demasiado de las necesidades reales de recursos para que tengan efecto en las exigencias populares. Eufemísticamente, concluyen los autores, se termina "dividiendo correctamente lo que sobra” (2000: 150), con lo cual es, por lo menos, ingenuo esperar que el presupuesto participativo posea un carácter pedagógico para el perfeccionamiento de la democracia. En todo caso, terminaría cumpliendo el rol de deseducar a la población en la medida en que ésta entraría en una

7 Este resultado, visto desde la perspectiva de los liderazgos de izquierda, sobre todo de inspiración marxista, que impulsan al presupuesto participativo, es un resultado deseable pues se trataría, con ello, de contribuir a la superación de la democracia formal burguesa e instaurar una democracia real, la participativa. Para llegar a ella, los líderes preclaros desde el Estado aspiran dirigir las masas prevalidos de la idea de que ellos conocen lo que más conviene al pueblo y al país. Esta forma de pensamiento se encuentra en la raíz de los movimientos populistas latinoamericanos, con lo cual sería imposible rearticular al Estado y la sociedad civil dentro de nuevas ciudadanías, dando al traste con el principio de autonomía antes señalado. 
atmósfera de confusión respecto de cuáles son los procedimientos decisorios legítimos, por lo menos en lo que a un sistema democrático liberal se refiere.

Para tener una dimensión sobre el significado de la Ley de Participación boliviana es necesario observar la siguiente afirmación: "la participación popular es lo mejor que hemos hecho los bolivianos en los casi últimos cincuenta años de historia republicana" (Rojas Ortuste: 2003: 7). Muy alta fue y ha sido la expectativa puesta sobre esta reforma. Sin embargo, al transcurrir del tiempo, surgen sus limitaciones. Con datos en mano, el autor informa acerca de la persistencia de los rasgos patrimoniales y caudillistas en el manejo municipal, con incrementos de corrupción sin sanción legal, toda vez que la sociedad apenas había puesto en práctica luego de nueve años de gestión popular- el voto de censura en apenas 19\% de los municipios. Para Miguel Urioste (2003), la descentralización municipalista con participación ciudadana directa fue una medida radical en el contexto político boliviano, inspirada en la experiencia de la diversidad de actores sociales y políticos. Como ya se señaló, el principal sujeto de dicha reforma radical fueron las comunidades indígenas, campesinas y juntas vecinales, reconocidas jurídicamente con el término de Organizaciones Territoriales de Base (Отв). A pesar de sus potenciales y evidentes bondades, el proceso ha sido objeto de numerosas críticas las cuales se resumen a continuación. En primer lugar, las instituciones previstas para la participación no están funcionando según las expectativas ideales, sobre todo por la mediatización de la cual han sido objeto producto del monopolio político partidista. Esta situación ha llevado a la cooptación de los Comités de Vigilancia, convertidos en espacios de reparto partidario. Una segunda limitación se encuentra en las estructuras de gobierno local. La mayoría de ellas son débiles tanto en su vertiente fiscal y de servicios como en las capacidades para conducir un proceso complejo de participación. En tercer lugar, persisten problemas en cuanto a la redefinición de lo público dentro del proceso de participación. Luego de una primera etapa, la Ley generó un efecto centrífugo cuando logró movilizar a centenas de organizaciones populares en el camino hacia la apropiación del proceso. Sin embargo, pasada la efervescencia inicial, se observa una etapa centrípeta donde el poder central se convierte en protagonista, aunado a una tendencia a la fragmentación institucional de la sociedad civil. En un escenario pesimista, señala Urioste, a pesar de la existencia de una incontestable realidad municipal en Bolivia, pudiera producirse un pro- 
ceso de modernización incorporativa, con lo cual se destruirían herencias indígenas y culturales, a pesar de la retórica de la participación popular.

Es evidente cómo, en ambos casos, la práctica real de la participación termina envuelta en y supeditada a los usos y costumbres que son dominantes en la relación Estado-sociedad (o gobierno-pueblo) en el acontecer histórico latinoamericano: la relación populista. Este modelo relacional construido en función de una política explícita de participación popular desde las décadas de los treinta y cuarenta, produjo una categoría de pueblo que se constituye dentro de una participación de carácter heterónomo que "se valida únicamente a través de la presencia de líderes políticos situados por encima del mundo popular. El pueblo no está constituido, pues, de un modo democrático como apropiación de un derecho de ciudadanía anterior al Estado [...] el pueblo existe sólo como masas confinadas en un estado de naturaleza (miseria) y desprovistas de lenguaje (como no sea la violencia), cuyo principio de organización debe provenir desde fuera" (Valenzuela, 1991: 12-13). En esta perspectiva, el concepto o noción de sociedad civil como esfera autónoma del Estado resulta absolutamente extraña y contrapuesta a este modelo de relación entre el Estado y la sociedad. Así, ante la permanente presencia de culturas populistas dominantes en la sociedad política latinoamericana, ¿̇es posible hablar de creación de ciudadanía en función de los procesos de participación? He aquí, en consecuencia, una de las limitantes centrales de la participación puesta en marcha, con base en la oferta desde el Estado descentralizado, desde hace tres décadas. ¿Será posible su superación?

\section{Comentarios finales}

Alexis de Tocqueville (1993) decía que lo que más le chocaba a los europeos cuando recorrían los Estados Unidos era la ausencia de gobierno o administración. En la tradición estadounidense, el derecho de aplicar la ley se encontraba repartido entre tantas manos que el poder existía, más no se sabía dónde se encontraba. Además, se quería que la autoridad de la sociedad fuera grande y el funcionario público pequeño, a fin de que la sociedad siguiera libre. Por ello, eran los municipios quienes -con los jueces de paz- regulaban los detalles de lo local mientras que, por el contrario, "el gobierno central no está representado por ningún hombre encargado de confeccionar reglamentos ge- 
nerales de policía u ordenanzas para la ejecución de leyes, estar en comunicación habitual con los administradores del condado y del municipio, inspeccionar su conducta, dirigir sus actos o castigar sus faltas" (Ibidem: 70). Eran los usos y costumbres fundacionales de la relación entre el Estado y la sociedad local que tanto admiraron a Tocqueville.

Como sabemos, en la tradición hispanocatólica la omnipresencia del Estado central monárquico en todos los actos de la vida de los territorios latinoamericanos fueron la norma, fueron los usos y costumbres, a pesar de la existencia de la institución municipal que funcionara con gran autonomía, ante la lejanía de las autoridades de mayor jerarquía.

Siglos después, en América Latina nos encontramos discutiendo cómo hacemos para que la sociedad adquiera una autonomía tal que pueda contrarrestar la omnipresencia del Estado. La impronta del tipo de Estado y, desde él, de construcción de la sociedad, mantiene su huella perenne en el comportamiento de la sociedad respecto del Estado y viceversa.

Entre una y otra tradición existen marcadas diferencias que conducen a prescripciones actuales también diferentes. Al respecto, Jean Cohen y Andrew Arato (2000) -al reflexionar sobre la realidad estadounidense- plantean la necesidad de recuperar la idea de sociedad civil de la tradición de la teoría política clásica, mediante un programa que persiga la representación de los valores e intereses de la autonomía social entre el Estado y la economía, siendo este camino la mejor manera de autoorganización y autoconstitución. En cuanto a la realidad latinoamericana, los autores ubican el resurgimiento de la sociedad civil en el marco de los regímenes autoritario-burocráticos, término clave para la autocomprensión de los actores democráticos y su transición a la democracia. Este nuevo estadio pareciera representar una superación de la tradición que en América Latina condujo a una sociedad sin profundas raíces organizativas, aunque movilizada por los populismos, condición que abonó el camino de su supresión por parte de los regímenes autoritarios.

Entre una y otra realidad, ¿̇algo ha cambiado? Ubiquémonos, por un instante, en un discurso omniabarcante: el de la modernidad. De acuerdo con Renato Ortiz (2000), se puede decir que en América Latina se levanta una tradición de la modernidad. A esta conclusión llega el autor al comparar las visiones y vivencias latinoamericanas de los años treinta, cuarenta y cincuenta cuando la modernidad era todavía un proyecto por construir respecto de 
la realidad de los setenta y ochenta en las que mucho de lo que se reclamaba se realizó. "La modernidad se vuelve así algo presente, en un imperativo de nuestros días, y ya no más una promesa deslocalizada en el tiempo. Modernidad problemática, controvertida, pero sin duda parte integrante del día a día" (Ibidem: 166). Aquel salto vino acompañado de un intenso proceso de racionalización impuesto consistentemente en una conjunción activa de las instituciones que se encargaran de ello: el Estado, las empresas, las universidades, los sindicatos (agrego los partidos políticos) quienes hicieron que América Latina se distanciara de manera sustancial de su pasado rural y arcaico, forjado en función de relaciones exclusivamente filiales y cercanas. A ello contribuyó, en definitiva -sostiene Ortiz-, la implantación de las industrias culturales. Cuando aquello se estaba formando, pasamos, de una vez, a una modernidad-mundo, cuando la nuestra todavía era una modernidad incompleta.

Es quizás el relato alrededor de la modernidad el que nos pueda ayudar a ensayar alguna inacabada respuesta final. Sin lugar a dudas, la democratización de Latinoamérica formó parte de aquella aspiración de modernidad de la primera mitad del siglo xx como también lo fue la aspiración de una sociedad a ejercer su autonomía de la esfera del poder. Décadas más tarde, el subcontinente entra en una oleada de democracias como reacción ante los autoritarismos dominantes, y luego de casi 30 años, se puede afirmar que el espectro político dominante es el de las instituciones democráticas, con lo que de asunción de valores ello implica. Sin embargo, no existe satisfacción con las democracias actuales; hay, por el contrario, un profundo desagrado. Así quedó revelado en el reciente informe del Programa de las Naciones Unidas para el Desarrollo (PNUD, 2004): 54\% de los ciudadanos latinoamericanos prefieren mantener algún nivel de satisfacción material, sobre todo la económica, aunque sea en regímenes menos democráticos. Es decir, no importan tanto las formas y fondos democráticos, siempre y cuando el autoritario de turno pueda satisfacer las expectativas más inmediatas. Y no debemos olvidar que, en definitiva, son los propios ciudadanos quienes legitiman al régimen de turno, sea de la orientación que fuese en cuanto a la preservación y los derechos de esos mismos ciudadanos.

Estas democracias incompletas se han nutrido de cambios en la complejidad de los patrones de asociatividad y organización de las sociedades latinoamericanas. De una lógica dominantemente arcaica, de vínculos familiares y de escasa o ninguna ex- 
presión de formas modernas, hemos asistido a una proliferación de estructuras sociales que tratan de incursionar en todos los ámbitos de la vida y de la acción pública. No se quiere decir que los patrones filiales han desaparecido y entramos en el terreno de la absoluta racionalidad weberiana, en el reino de lo impersonal. Sin embargo, hay que aceptar que la diferenciación funcio$\mathrm{nal}^{8}$ de las sociedades contemporáneas, proceso presente en América Latina a propósito de su inserción (incompleta) en la modernidad, ha hecho emerger una multiplicidad de organizaciones sociales que se desparraman a lo largo de la trama institucional. De este fenómeno forman parte los esfuerzos por descentralizar el poder del Estado, en una reacción para responder a ese desborde que amenazaba ( $\mathrm{y}$ amenaza constantemente) con convertir en obsoleto al denostado Estado latinoamericano. Y dentro de ese fenómeno habrá que tratar de comprender también el establecimiento de múltiples conexiones de la sociedad con el Estado, aun proviniendo la oferta de conectividad fundamentalmente desde el Estado, pero que no existiría sin la presión de las organizaciones sociales.

No se trata de un dilema, tampoco de un juego suma cero. Conviene mirar la relación entre la sociedad civil y el Estado descentralizado como parte de una realidad cambiante, que arrastra lastres de premodernidad, sobre todo de relaciones patrimoniales asimétricas, pero que en ningún momento es igual a las relaciones exclusivamente filiales cuando apenas se aspiraba a incorporar los patrones de modernidad, donde destacaba la aspiración a la democracia.

¿Hasta qué punto es posible generar una representación perdurable de la sociedad civil latinoamericana en la arena de los asuntos públicos? Existe un reto teórico y práctico para repensar la conexión entre la representación política y los movimientos sociales, de manera que se pueda conservar la apertura de ambas esferas, sostienen Levine y Romero, toda vez que "los lazos entre los espacios civiles de empoderamiento y los espacios públicos de representación política, por un lado, y el poder estatal, por otro, siguen siendo problemáticos" (2004: 58). La ya vieja aspiración de los movimientos sociales a una pretendida

\footnotetext{
${ }^{8}$ El fenómeno de la diferenciación funcional de los sistemas sociales modernos lo ha desarrollado ampliamente Niklas Luhmann en varias de sus obras. Uno de los trabajos que aborda el tema de manera extensa es el capítulo "La diferenciación de la sociedad", en Complejidad y modernidad. De la unidad a la diferencia, editado por Trotta bajo la coordinación de Josexto Beriain y José María García Blanco, Madrid, 1998.
} 
autonomía fue exagerada, por lo que no germinó una nueva clase política de las semillas sembradas por esos movimientos. Las fronteras entre empoderamiento y clientelismo siguen siendo frágiles y borrosas. El surgimiento de regímenes autocráticos como los de Fujimori y Chávez hacen retroceder la independencia de los movimientos sociales y los procesos de descentralización. Por tales razones, sostienen Daniel Levine y Catalina Romero, no es fácil ser optimista respecto del futuro de los movimientos urbanos. Pero ante el poco optimismo o el mucho pesimismo, es conveniente tener presente que ese espacio de la sociedad civil no resulta ser "un campo ordenado donde cada actor conoce sus límites e interactúa por medio de instituciones estables [toda vez que] la transición produce actores híbridos y muchas veces efímeros que disuelven las fronteras entre el 'movimiento social', el grupo de presión y la organización política, que en algunos casos se enfrentan radicalmente al Estado y en otros dependen de su protección para sobrevivir" (Gómez Calcaño, 2006: 2). De allí que las organizaciones civiles han enfrentado el dilema de ocupar amplias y ambiguas zonas entre lo social y lo político, donde surgieron organizaciones sociales promovidas por el propio Estado o aparecieron espacios locales para la deliberación y la decisión.

Como si poca fuera la complejidad que se adueña de este campo, hay algo más que comprender: las agendas de los movimientos han cambiado. No sólo se demanda tierra, agua, vivienda, transporte, educación o seguridad, sino que se imponen reclamos por el acceso a la representación política. Esta aspiración supone relaciones viables con los distintos niveles de gobierno. Allí, entonces, la conexión con las formas de representación descentralizadas -concluimos-, continúa siendo una arena conveniente e indispensable para articular a la sociedad civil territorial en condiciones de mayor autonomía. Así, la respuesta final es muy modesta y sencilla: algo está cambiando. Pero no un cambio radical, como muchos ilusoriamente esperarían. Se trata de cambios con altas dosis de contingencia, realidad en la cual los resultados que se obtienen no necesariamente complacen de manera cabal las expectativas formadas alrededor de los procesos de descentralización, tal como fueran diseñados y argumentados inicialmente. Pareciera que nos moveremos, permanente y crecientemente, en una constante insatisfacción y ello forma parte de la incorporación de los valores de la modernidad en América Latina. 


\section{Bibliografía}

Albuquerque, Francisco (1999), "Gobiernos locales y desarrollo económico en América Latina y el Caribe", en La dimensión de lo local: enfoque territorial, tejido productivo local, concertación de actores y aprendizaje para la acción, Fundación Friedrich Ebert, Santiago de Chile, Chile, pp. $35-51$.

Araujo, María Ceci (2001), "La relación entre ciudadanía activa y administración municipal en la configuración de una formación político-organizacional: los casos del Proyecto de Salud Mental de Belo Horizonte y del Presupuesto Participativo de Porto Alegre”, Reforma y Democracia, 21, CLAD, Caracas, Venezuela, pp. 189-226.

Arroyo, Daniel (1997), "Estilos de gestión y políticas sociales municipales en Argentina", en Daniel García D. (comp.), Hacia un nuevo modelo de gestión local: municipio y sociedad civil en Argentina, FLACSO-Universidad de Buenos Aires-Universidad Católica de Córdoba, Buenos Aires, Argentina, pp. 315-328.

Azpur, Javier (2003), "Luces y sombras de una posibilidad democratizadora", Foro Descentralista, 2, Grupo Propuesta Ciudadana, Lima, Perú, pp. 4-10.

Barbery, Roberto (1998), "Una revolución en democracia", en Nueva Sociedad, El pulso de la democracia. Participación ciudadana y descentralización en Bolivia, Nueva Sociedad, Caracas, Venezuela, pp. 59-74.

Bardhan, Pranab (2002), "Decentralization of governance and development", The Journal of Economic Perspectives, 16(4), American Economic Association, Pittsburgh, Estados Unidos, pp. 185-205.

Bervejillo, Federico (1991), “Gobierno local en América Latina. Casos de Argentina, Chile, Brasil y Uruguay", en Dieter Nohlen (ed.), Descentralización política y consolidación democrática. Europa-América del Sur, Nueva Sociedad, Caracas, Venezuela, pp. 279-300. 
Betancourt, Mauricio (2001), Elementos a tener presentes en la construcción de metodologías participantes en el proceso de la planificación del desarrollo local para municipios pequeños, medianos y comunas o localidades de las grandes ciudades colombianas, Escuela Superior de Administración Pública, Bogotá, Colombia, mimeo.

Cabrero-Mendoza, Enrique (1996), "Las políticas descentralizadoras en el ámbito internacional. Retos y experiencias", Nueva Sociedad, 142, Caracas, Venezuela, pp. 72-95.

Cabrero-Mendoza, Enrique (2005), Acción pública y desarrollo local, México, Fondo de Cultura Económica.

Calderón, Jorge (2001), Balance de la descentralización y la reforma municipal en Centroamérica y República Dominicana, San José, República Dominicana, OEA, mimeo.

Campero, José Carlos y George Gray-Molina (2000), "Proyecto de investigación sobre el proceso de participación popular en Bolivia”, París, Francia, mimeo.

Carrizo, Cecilia (1997), "Intervención estatal y organizaciones sociales. El Consejo Económico y Social de la provincia de Córdoba, 1985-1993”, Administración Pública, 10, Universidad de Córdoba, Córdoba, Argentina, pp. 122-147.

Cavalcanti, Elvia y Reynaldo Maia (2000), "Contradicciones en un proceso democrático: la práctica del presupuesto participativo en las ciudades brasileñas”, Reforma y Democracia, 18, ClAD, Caracas, Venezuela, pp. 131-154.

Cavarozzi, Marcelo (1995), "Más allá de las transiciones a la democracia en América Latina”, en José Luis Reyna (comp.), América Latina a fines de siglo, Fondo de Cultura Económica, México, pp. 460-485.

Cavo P., Beatriz (1998), Nuevas formas de gestión escolar: experiencias en el estado de Chihuaha, México, México, Universidad Autónoma de Ciudad Juárez-Centro de Investigaciones y Estudios Superiores en Antropología Social, mimeo. 
Clemente, Adriana (2000), "La relación Estado y sociedad. Enfoque y procedimientos para el consenso", Pobreza Urbana y Desarrollo, año 9, 20, IIED, Buenos Aires, Argentina, pp. 3-4.

Cohen, Jean y Andrew Arato (2000), Sociedad civil y teoría politica, México, Fondo de Cultura Económica.

Cummings, Andrew (2002), Contraloría social en el ámbito local en El Salvador. Lecciones y propuesta metodológica, San Salvador, FUNDE-CDC-Fedecoopades-Las Dignas-Oxfam América.

Cunill-Grau, Nuria (1991), Participación ciudadana. Dilemas y perspectiva para la democratización de los Estados latinoamericanos, CLAD, Caracas, Venezuela.

Cunill-Grau, Nuria (1995). "La rearticulación de las relaciones Estado-sociedad: en búsqueda de nuevos sentidos", Reforma y Democracia, 4, CLAD, Caracas, Venezuela, pp. 25-58.

Cunill-Grau, Nuria (1997), Repensando lo público a través de la sociedad. Nuevas formas de gestión pública y representación social, Caracas, Venezuela, CLAD-Nueva Sociedad.

Chalmers, Douglas (2001), "Vínculos de la sociedad civil con la política. Las instituciones de segundo nivel", Nueva Sociedad, 171, Caracas, Venezuela, pp. 60-87.

Díaz de Landa, Martha (1991), "Descentralización nacional y provincial en el marco de la reforma del Estado en Argentina”, en Dieter Nohlen (ed.), Descentralización política y consolidación democrática. Europa-América del Sur, Nueva Sociedad, Caracas, Venezuela, pp. 301-322.

Eaton, Kent y J. Tyler Dickovick (2004), “The politics of Recentralization in Argentina and Brazil", Latin American Research Review, 39(1), LASA, University of Texas Press, pp. 90-112.

Escobar, Arturo, Sonia Álvarez y Evelina Dagnino (2001), "Lo cultural y lo político en los movimientos sociales latinoa- 
mericanos", en Arturo Escobar, Sonia Álvarez, Evelina Dagnino, Política cultural y cultura política, Taurus, Bogotá, Colombia, pp. 15-50.

Ferrarezi, Elisabete (2001), "El nuevo marco del tercer sector en Brasil”, Reforma y Democracia, 20, CLAD, Caracas, Venezuela, pp. 35-72.

Friedmann, Reinhard y Margarita Llorens (2000), "Ciudadanización y empowerment. Formas alternativas de participación ciudadana local", Cuadernos de Análisis, 4, Universidad Central de Chile, Santiago, http:// www.chasque.apc.org.

Gallicchio, Enrique y Alejandra Camejo (2005), Desarrollo local $y$ descentralización en América Latina. Nuevas alternativas de desarrollo, Montevideo, Uruguay, CLAEH-Diputació Barcelona.

Giannoni, Tonya (2004), Decentralization and Democracy, XXV LASA Congress, Las Vegas, mimeo.

Gómez-Álvarez, David (2002), "Reconstruir el federalismo: relaciones intergubernamentales y descentralización educativa en México", en Sonia Ospina y Michael Penfold (eds.), Gerenciando las relaciones intergubernamentales. Experiencias en América latina, Nueva Sociedad, Caracas, Venezuela, pp. 59-92.

Gómez-Calcaño, Luis (2006), La disolución de las fronteras: sociedad civil, representación y politica en Venezuela, Caracas, Área de Desarrollo Sociopolítico-Centro de Estudios del Desarrollo-Universidad Central de Venezuela, mimeo.

Gómez-Calcaño, Luis (1992), "Movimientos sociales y democratización en América Latina", Cuadernos del Cendes, 19, CENDEs, Caracas, Venezuela, pp. 9-40.

González-Alcantud, José (1997), El clientelismo político. Perspectiva socioantropológica, Barcelona, España, Antrophos. 
Gorlier, Juan Carlos (1992), “Democratización en América del Sur: una reflexión sobre el potencial de los movimientos sociales en Argentina y Brasil", Revista Mexicana de Sociología, año LIv, 4, México, pp. 119-152.

Göske, Joachim (1999), "Desarrollo territorial: hacia un enfoque sistémico integrador", en La dimensión de lo local: enfoque territorial, tejido productivo local, concertación de actores y aprendizaje para la acción, Fundación Friedrich Ebert, Santiago de Chile, pp. 5-34.

Grupo Propuesta Ciudadana (2003), Vigila Perú. Sistema de vigilancia ciudadana de la descentralización, Reporte Nacional, 1, primer semestre, Lima, Perú.

Grupo Propuesta Ciudadana (2004), Vigila Perú. Sistema de vigilancia ciudadana de la descentralización, Reporte Nacional, 3, cuarto trimestre 2003, Lima, Perú.

Haldenwang, Christian von (1990), Hacia un concepto politológico de la descentralización del Estado en América Latina, Eure, BD, 16, H.50.

Hengstenberg, Peter (1999), "La política comunal como área de trabajo de la Fundación Friedrich Ebert", en Fundación F. Ebert, Descentralización y autonomía comunal: la creación de espacios para un nuevo estilo de politica, Fundación Friedrich Ebert, Santiago de Chile, pp. 11-45.

Hirschman, Albert O. (1986), El avance en colectividad. Experimentos populares en la América Latina, México, Fondo de Cultura Económica.

Jaramillo, Iván (1992), "El nuevo sistema financiero de las entidades territoriales", en FESCOL, Estado y nuevo régimen territorial, FESCOL-FAUS, Bogotá, Colombia, pp. 87-116.

Karl, Terry Lynn (1995), "Dilemas de la democracia en América Latina”, en José Luis Reyna (comp.), América Latina a fines de siglo, Fondo de Cultura Económica, México, pp. 432-459. 
Kärner, Hartmut (1983), “Los movimientos sociales: revolución de lo cotidiano", Nueva Sociedad, 64, Caracas, Venezuela, pp. 25-32.

Lechner, Norbert (1992), "Reflexión acerca del Estado democrático", Leviatán, segunda época, Editorial Pablo Iglesias, Madrid, España, pp. 87-94.

Lechner, Norbert (1994), "Los nuevos perfiles de la política. Un bosquejo", Nueva Sociedad, 130, Caracas, Venezuela, pp. $32-43$.

Lechner, Norbert (2000), "Desafíos de un desarrollo humano: individualización y capital social”, Instituciones y Desarrollo, 7, Instituto Internacional de gobernabilidad, www.iigov.org.

Levine, Daniel y Catalina Romero (2004), "Movimientos urbanos y desempoderamiento en Perú y Venezuela”, América Latina Hoy, 36(99), Universidad de Salamanca, España, pp. 47-77.

Londoño, Juan F. (1998), "La promoción de la participación en el nivel local", en Ministerio del Interior, Democracia participativa y fortalecimiento de la sociedad civil, Ministerio del Interior, Bogotá, Colombia, pp. 147-152.

López, Silvana (1997), "La revocatoria popular: un instrumento que amplía y fortalece la democracia”, Córdoba, 10, Universidad Nacional de Córdoba, España, pp. 93-100.

Luhmann, Niklas (1998), "Diferenciación social y sociedad moderna”, en Josetxo Beriain y José María García Blanco, Complejidad y modernidad, de la unidad a la diferencia, Trotta, Madrid, España, pp. 71-214.

Llona, Mariana y Mario Zolezzi (2000), "Planes estratégicos de desarrollo local. La experiencia de Villa El Salvador, Lima", Pobreza Urbana y Desarrollo, año 9, 20, IIED, Buenos Aires, Argentina, pp. 18-22. 
Magnani, César (1992), La descentralización administrativa y la participación de los usuarios en la administración hídrica mendocina, Mendoza, s.e., mimeo.

Maranhao, Pedro (1991), "Descentralización en Brasil”, en Comisión Presidencial de la Reforma del Estado, La descentralización y las autonomías territoriales. La experiencia internacional, COPRE, Caracas, Venezuela, pp. 281-288.

Marsiglia, Javier (2000), "Desarrollo local en Colonia”, Pobreza Urbana y Desarrollo, año 9, 20, IIED, Buenos Aires, Argentina, pp. 55-61.

Mascareño, Carlos (2000), Balance de la descentralización en Venezuela: logros, limitaciones y perspectivas, PNUD-Nueva Sociedad, Caracas, Venezuela.

Mascareño, Carlos (2005a), "Federalismo unitarismo: semejanzas y diferencias de los procesos de descentralización de Venezuela y Perú”, Territorios, 14, Bogotá, Colombia, pp. 83-104.

Mascareño, Carlos (2005b), "Descentralización, recentralización y sociedad civil”, en Cendes-BID, Venezuela visión plural, una mirada desde el Cendes, Cendes-BID, Caracas, Venezuela, pp. 146-163.

Mercado, José F. y Heber Olmos V. (1997), "La participación social en la administración pública: caso de estudio del estado de Baja California", Gaceta Mexicana de Administración Pública Estatal y Municipal, 58, México, pp. 75-81.

Mizrahi, Yemile (2004), "Mexico: Decentralization from Above", en Joseph Tulchin y Andrew Selee (eds.), Decentralization and democratic governance in Latin America, Woodrow Wilson Center, Washington D. C., pp. 137-166.

Molina, Carlos Hugo (1997a), La participación en el sistema educativo de Bolivia, La Paz, Ministerio de Desarrollo Humano, Documentos Relaciones Internacionales, mimeo. 
Molina, Carlos Hugo (1997b), "Participación popular y descentralización: instrumentos para el desarrollo", en El pulso de la democracia. Participación ciudadana y descentralización en Bolivia, Nueva Sociedad, Caracas, Venezuela, pp. 39-44.

Olvera, Alberto (2003), “Introducción”, en Alberto Olvera (coord.), Sociedad civil, esfera pública y democratización en América Latina, Fondo de Cultura Económica, México, pp.13-39.

Olvera, Alberto y Leonardo Avritzer (1992), "El concepto de sociedad civil en el estudio de la transición democrática", Revista Mexicana de Sociología, 4, México, pp. 227-248.

OPS (Organización Panamericana de la Salud) (2002), Municipios y comunidades saludables. Celebrando 100 años de salud, Washington, D. C., OPS.

Ortiz, Renato (2000), "América Latina. De la modernidad incompleta a la modernidad-mundo", Nueva Sociedad, 137, Caracas, Venezuela, pp. 44-61.

Oxhorn, Philip (2001), La construcción del Estado por la sociedad civil: la Ley de Participación Popular de Bolivia y el desafío de la democracia local, Documentos de trabajo del INDE-BID, Washington, D. C.

Oxhorn, Philip (2003), "Cuando la democracia no es tan democrática. La exclusión social y los límites de la esfera pública en América Latina", Revista Mexicana de Ciencias Políticas y Sociales, 187, México, pp. 131-176.

Pease García, Henry (1983), "Vanguardia iluminada y organización de masas", Nueva Sociedad, 64, Caracas, Venezuela, pp. 33-38.

PNUD (Programa de las Naciones Unidas para el Desarrollo) (2004), La democracia en América Latina. Hacia una democracia de ciudadanas y ciudadanos, Washington, D. C., PNUD.

Quero, Morgan (2004), "De la ley de la calle a la ley de las élites: la sociedad civil en la encrucijada en América Latina", 
Economía, Sociedad y Territorio, 16, El Colegio Mexiquense, México, pp. 657-670.

Quero, Morgan (2003), "El arte de la asociación o una periferia que puede ser centro. Sociedad civil y gobernabilidad en Morelos", en Alberto Olvera (coord.), Sociedad civil, esfera pública y democratización en América Latina, Fondo de Cultura Económica, México, pp. 149-204.

Quesada, Silvia y Alberto Cuello (1999), Gestión para la reforma del Estado. Análisis y evaluación de los programas sociales descentralizados a través de los Consejos Sociales departamentales, nivel municipal, Mendoza, Universidad Nacional de Cuyo, Argentina, mimeo.

Rabotnikof, Nora (1992), "El retorno de la filosofía política: notas sobre el clima teórico de una década”, Revista Mexicana de Sociología, 4, México, pp. 209-225.

Red Perú (2002), Construyendo la gobernabilidad democrática desde los espacios regionales y locales, v Encuentro $\mathrm{Na}$ cional de Iniciativas de Concertación para el Desarrollo Local, Lima, Red Perú.

Restrepo, Darío (2003), "Las prácticas participativas: entre la socialización y la privatización de las políticas públicas”, Reforma y Democracia, No. 25, CLAD, Caracas, Venezuela, pp. 87-124.

Restrepo, Darío (2001), "Eslabones y precipicios entre participación y democracia”, Revista Mexicana de Sociología, 3, México, pp. 167-191.

Rey, Eduardo (1992), Participación ciudadana y gestión pública: una sistematización de experiencias emergentes del constitucionalismo provincial, Paraná, Brasil, s.e., mimeo.

Ritchey-Vance, Marion (1996), El capital social, la sostenibilidad y la democracia en acción: nuevas medidas para la evaluación del desarrollo de base, Arlington, Virginia, Fundación Interamericana. 
Rivarola, Magdalena y Brice Fuller (1998), "El experimento en Nicaragua para descentralizar las escuelas: perspectivas desde los padres, maestros y directores", Revista Paraguaya de Sociología, año 35, 103, Asunción, Paraguay, pp. 11-51.

Rivera, Roy (2004), "Centroamérica: entre el discurso de la modernización institucional y las resistencias del centralismo", Quórum, 8-9, Universidad de Alcalá, Alcalá de Henares, España, pp. 34- 45.

Rofman, Adriana y Marisa Fournier (2004), "El desarrollo local como modelo alternativo de política social: una reflexión sobre modelos, estrategias y territorios", en Desarrollo local/regional y descentralización, Arequipa, I Cumbre Latinoamericana, Ceder-Diputació Barcelona-IAF, España, pp. 198-219.

Rojas-Ortuste, Gonzalo (2003), Evaluación de la democracia boliviana y prospectiva, Seminario Internacional Balance de la democracia en la región Andina, Lima, Perú, Grupo Propuesta Ciudadana-ALOP, mimeo.

Rosanvallon, Pierre (2006), "La crisis de la democracia", conferencia en la Facultad de Ciencias Económicas y Sociales, Universidad Central de Venezuela, Venezuela, 17 de noviembre.

Salamanca, Luis (1989), “¿Dónde están los nuevos movimientos sociales?”, Revista sic, 520, Centro Gumilla, Caracas, Venezuela, pp. 464-466.

Saldomando, Ángel y Rokael Cardona (2005), Descentralización, desarrollo local y gobernabilidad en Centroamérica, San Salvador, Confedelca.

Smulovitz, Catalina y Adriana Clemente (2004), "Decentralization and social expenditure at the municipal level in Argentina", en Joseph Tulchin y Andrew Selee (eds.), Decentralization and democratic governance in Latin America, Woodrow Wilson Center, Washington D. C., pp. 101-136. 
Spehar, Elizabeth (2001), Perspectivas comparadas de los procesos de descentralización en el hemisferio: lecciones aprendidas y desafíos futuros, Washington, D. C., OEA-Unit for the Promotion of Democracy, versión preliminar, mimeo.

Thevoz, Laurent y Ernesto Velasco (1998), "La dinámica de los procesos municipales de implementación de la LPP”, en Participación popular: una evaluación-aprendizaje de la Ley 1994-1997 Bolivia, Viceministerio de Participación Ciudadana y Fortalecimiento Municipal, La Paz, pp. 201-222.

Tocqueville, Alexis de (1993), La democracia en América, Madrid, España, Alianza.

Uribe, Gabriela (1987), "Nuevos movimientos sociales, tejido social alternativo y desarrollo científico-tecnológico: algunas tesis prospectivas", David y Goliat, 51, Clacso, Buenos Aires, Argentina, pp. 48-55.

Urioste, Miguel (2003), Descentralización municipal y participación popular, Seminario Internacional "Balance de la democracia en la región Andina”, Grupo Propuesta Ciudadana-Alop, Lima, Perú, mimeo.

Valenzuela, Eduardo (1991), "La experiencia nacional-popular", Proposiciones, 20, Ediciones Sur, Chile, pp. 12-33.

Varela, Édgar (2000), Los gobiernos locales como ejecutores de la política social y la promoción del desarrollo: el caso colombiano, Universidad del Valle, Cali, Colombia, mimeo.

Velásquez, Fabio (2004), "Colombia: ¿de regreso a un esquema centralista?, Quórum 8-9, Universidad de Alcalá, Alcalá de Henares, pp. 46-57.

Verdesoto, Luis (1998), "Los conceptos de participación y descentralización mirados desde el caso boliviano", Reforma y Democracia, 12, CLAD, Caracas, Venezuela, pp. 109-142.

Weber, Max (1992), Economía y sociedad, México, Fondo de Cultura Económica. 
Ziccardi, Alicia (1999), Comentarios sobre las posibilidades de la gestión local del desarrollo: ciudades y ciudadanía, México, Universidad Nacional Autónoma de México, mimeo.

Recibido: 26 de septiembre de 2006. Reenviado: 16 de marzo de 2007. Aceptado: 4 de junio de 2007.

Carlos Mascareño Quintana. Es doctor en estudios del desarrollo por el Centro de Estudios del Desarrollo (Cendes), de la Universidad Central de Venezuela; master en planificación y actualmente realiza un PostDoctoral Fellowship en el Latin American Studies Center (LASC), en la Universidad de Maryland. Es profesor titular del Cendes. Sus líneas de investigación se centran en: descentralización, sociedad civil y políticas públicas. Sus publicaciones más recientes son: "Venezuela: no se hacen revoluciones sin unidad de mando", en Darío Restrepo (coord.), Historias de la descentralización: transformación del régimen politico y cambio en el modelo de desarrollo, Bogotá, Universidad Nacional de Colombia, pp. 137-177 (2007); "Die Dezentralisierung in Venezuela unter der Chavez-Regierung”, en coautoría con Beate Jungeman, en Kersting et al., Kulturgeographische Regionalstudien. Festscrhift zum 60. Geburrtstag von Heinrich Pachner. Regiones im Fokus der Forschung (Riff) Band 6, Rotemburgo, pp. 181-206 (2006); "Consenso político para descentralizar el federalismo centralizado venezolano", Politeia, 37-38, ucv, Caracas, pp. 113-169 (2005); "Descentralización, recentralización y sociedad civil", en CENDES/UCV, Venezuela: visión plural, Caracas, Cendes, pp. 146-165 (2005); "Descentralización, empresariado y economía territorial”, Revista Banco Central de Venezuela, Foro 11, Caracas, pp. 85-102 (2005); "Federalismo y unitarismo: semejanzas y diferencias de los procesos de descentralización de Venezuela y Perú", Revista Territorios, 14, Universidad de Los Andes, Bogotá, pp. 83-104 (2005). 